\title{
Hybrid intelligence in hospitals: towards a research agenda for collaboration
}

\author{
Milad Mirbabaie ${ }^{1}$ (D) Stefan Stieglitz ${ }^{2}$. Nicholas R. J. Frick ${ }^{2}$ \\ Received: 20 March 2020 / Accepted: 5 January 2021 / Published online: 20 March 2021 \\ (C) The Author(s) 2021, corrected publication 2021
}

\begin{abstract}
Successful collaboration between clinicians is particularly relevant regarding the quality of care process. In this context, the utilization of hybrid intelligence, such as conversational agents (CAs), is a reasonable approach for the coordination of diverse tasks. While there is a great deal of literature involving collaboration, little effort has been made to integrate previous findings and evaluate research when applying CAs in hospitals. By conducting an extended and systematic literature review and semi-structured expert interviews, we identified four major challenges and derived propositions where in-depth research is needed: 1) audience and interdependency; 2) connectivity and embodiment; 3) trust and transparency; and 4) security, privacy, and ethics. The results are helpful for researchers as we discuss directions for future research on CAs for collaboration in a hospital setting enhancing team performance. Practitioners will be able to understand which difficulties must be considered before the actual application of CAs.
\end{abstract}

Keywords Hybrid intelligence $\cdot$ Conversational agents $\cdot$ Hospitals $\cdot$ Collaboration $\cdot$ Research agenda $\cdot$ Coordination

JEL classifications I00

\section{Introduction}

The introduction of conversational agents (CAs) holds immense potential for hospitals (e.g., Han and Yang 2018; Laranjo et al. 2018; Seeger et al. 2017) to improve collaboration between medical professionals and the coordination of health-related tasks (Georgiadis 2011; Just et al. 2005).

Responsible Editor: Philipp Alexander Ebel

This article is part of the Topical Collection on Hybrid Intelligence in Business Networks

Milad Mirbabaie

milad.mirbabaie@uni-bremen.de

Stefan Stieglitz

stefan.stieglitz@uni-due.de

Nicholas R. J. Frick

nicholas.frick@uni-due.de

1 Department of Business Studies and Economics, University of Bremen, 28359 Bremen, Germany

2 Professional Communication in Electronic Media / Social Media, University of Duisburg-Essen, 47057 Duisburg, Germany
Hospitals aim to enhance the overall service quality and levels, ultimately providing better medical care for patients (Majeed Alhashem et al. 2011). The quality of healthcare is described as subjective, complex and of multidimensional perception influenced by several factors (Mosadeghrad 2014). Besides professional skills (e.g., competence of clinicians) or medical experiences (e.g., physicians having sufficient expertise), interpersonal factors regarding human resources are vital (Mosadeghrad 2013). Thereby, the exchange of information and the degree of interaction between clinicians are explained as major criteria (Handayani et al. 2015). Mosadeghrad (2014) expresses that clinicians' competence to effectively communicate and collaborate with other healthcare specialists is essential to deliver high-quality healthcare services. Reaching effective communication and collaboration requires the involvement and coordination of different healthcare professionals who follow various norms or specifications with ranging roles from multiple departments (Charette 2006; Platt et al. 2019). However, clinicians largely manage their tasks in isolation with a lack of mutual understanding and cooperation. This silo thinking hinders sharing knowledge across departmental boundaries (McCracken and Edwards 2017), preventing collaboration between multiple disciplines and encourages competitive behavior (Driscoll et al. 2015). High 
administrative effort leads to delays in the treatment process for which departments blame each other (Girotto et al. 2010) and expose patients to potential safety hazards when transferring them between disciplines (Driscoll et al. 2015). Goaloriented collaboration among hospital employees is a key aspect in managing the coordination of tasks and thus mitigating errors during the treatment process creating safe systems of care delivery (Babiker et al. 2014; Rosen et al. 2018). Collaboration and information exchange is of great relevance to coordinate tasks and to ensure accurate, safe, and effective patient treatment (Gilbert et al. 2010; McInnes et al. 2015).

Interacting with CAs facilitates collaboration and promotes the coordination of health-related tasks (Georgiadis 2011; Just et al. 2005). For example, CAs monitor patient's overall health conditions to support the healing and regeneration processes (Pereira et al. 2013), improve the accuracy and timeliness of treatment (Atherton et al. 2013), and enhance the diagnostic and therapeutic process (Ferlie and Shortell 2001). The application of CAs also leads to effective team building and better team spirit among colleagues (Bittner, Küstermann, et al., 2019; Dyke et al. 2013; Strohmann et al. 2018). These improvements are especially beneficial in hospitals for the collaborative diagnosis of diseases and the development of treatment plans across multiple departments without the need for peer to peer collaboration. The development of CAs is enabled by artificial intelligence (AI) as building systems become more practicable (Knijnenburg and Willemsen 2016; Luger and Sellen 2016). CAs are initially intelligent systems interacting with and augmenting humans' abilities (McTear et al. 2016). However, there are different aspects of intelligent behavior. First, there are systems that respond to a certain input with a simple predefined reaction or reflex (Russel and Norvig 2016). Second, there are agents, which are lying within the scope of this research, that continuously learn and develop over time (Mitchell et al. 2018). Such learning agents acquire information through different types of knowledge and input or by multiple years of experience (Mitchell et al. 2018). Since interactions with CAs aim to combine the complementary strengths of users and AI (Kamar 2016; Maedche et al. 2019), they can be considered a subset of hybrid intelligence (Dellermann et al. 2019a), a concept with "the ability to achieve complex goals by combining human and artificial intelligence, thereby reaching superior results to those each of them could have accomplished separately, and continuously improve by the ongoing learning from each other" (Dellermann et al. 2019b, p. 4). Complementary strengths explain the different capabilities of humans and CAs. Humans possess emotional intelligence and the ability to empathize with others; are creative, think outside the box, and develop possibilities for innovations; are flexible, adapt to different or unexpected situations, and take responsibility. CAs, on the contrary, are fruitful for tackling repetitive tasks, which require the fast retrieval and processing of huge amounts of digital information and the interpretation of complex interdependencies (Dellermann et al. 2019b). Hybrid intelligence is described by the following three main concepts (Dellermann et al. 2019b): Collectively explains that tasks are solved together by humans and systems. Superior results refer to the performance on jointly solved tasks being better compared to solving a problem alone. Continuous learning characterizes that both humans and systems develop and improve over time by learning from each other through experience. Hybrid intelligence and therefore CAs provide humans with input, which is evaluated to make a decision (e.g., AI in the loop of human intelligence), and humans provide CAs with input to make them more effective (e.g., human intelligence in the loop of AI) (Dellermann et al. 2018; Dellermann et al. 2019b).

Hospitals have distinctive domain-specific requirements for the coordination of tasks (Aanestad and Vassilakopoulou 2019; Hanseth and Bygstad 2015). The interaction between healthcare specialists and CAs is suitable for tackling these issues (Seeber et al. 2018), for example, by providing the most relevant information to hospital employees to fulfill a duty without any delay (Diederich et al. 2019; Preece et al. 2017). Information systems (IS) are currently insufficiently integrated into the daily clinical routine, where medical information is distributed over several databases (Meier et al. 2014) and the vast amount of information is difficult to handle (PradosSuárez et al. 2012). CAs are able to obtain relevant data immediately as they are capable of better understanding complex interdependencies and gathering relevant information quicker than humans (Nasirian et al. 2017). The increasing capabilities of CAs lead to the pressing need of rethinking their collaboration with humans within the IS discipline. The complexity of the overall treatment process and the obligation of hospitals to decrease expenses drives the demand to explore new opportunities to enhance collaboration (Klinker et al. 2019; McInnes et al. 2015). It is necessary to consider CAs in terms of their phenomenon of improving collaboration and their capability of the coordination of diverse tasks (Dellermann et al. 2019b; Seeber et al. 2018). CAs offer novel challenges for collaboration and task coordination, including extending expertise and the joint completion of tasks (Dellermann et al. 2019b). The introduction of CAs has the potential to improve collaborative processes within hospitals; however, exploring new functionalities of healthcare information technology has proven to be demanding for IS research (Romanow and Straub 2012).

Undesirable outcomes as a result of failures in collaboration might have disastrous consequences for the patient's health condition (Jain 2006; Leonard 2004). If CAs become widely used to improve collaboration, they could feasibly coordinate different tasks and not just be of great value for applications in hospitals but also for the patients' general wellbeing. However, a full conceptualization of the challenges when introducing CAs to improve collaboration in hospitals is still lacking. We argue that this is of great interest to researchers and practitioners since its relevance will increase even further. Despite CAs' potential, there is not enough 
research conducted on the exploration of the challenges in a team setting (Diederich et al. 2019). There is a pressing need for the IS discipline to provide an overview of the challenges for understanding the complexity of the application of CAs in hospitals. In addition, an agenda that gives special consideration regarding what research is needed to successfully establish CAs for this purpose is overdue. To address these urgent issues, our study is guided by the following research question:

RQ: How does the interaction between humans and conversational agents affect the quality of care process?

We carried out a systematic literature review (SLR) because the complexity of the interaction between humans and CAs has not yet been adequately covered in the extant research, and there is no overview of the major challenges that appear when CAs are introduced in hospitals. This descriptive approach examined preexisting literature describing the current situation based on scientific facts (Bear and Knobe 2016; Bell 1989) and summarized the findings under a suitable heading where literature has dealt with identical or similar issues. We further conducted expert interviews to discover the consequences of the reviewed challenges. In this prescriptive procedure, the experts described impacts of existing problems, defined how obstacles should be addressed, and recommended purposeful actions (Bear and Knobe 2016; Bell 1989).

This paper contributes by structuring our understanding of collaboration and difficulties of CAs in hospitals. Researchers will find the overview of challenges helpful to consider potential difficulties before the actual introduction of CAs. To guide researchers' efforts, we outline an agenda explaining where future research of CAs and collaboration within hospitals seems promising. Practitioners will be able to understand the extent to which CAs improve collaboration and how hospitals, stakeholders and patients benefit. This article seeks to extend the IS literature by identifying areas that need further investigation and challenges that have not yet been adequately addressed.

\section{Related work}

\section{Collaboration in clinical environments}

Collaboration is a key factor in coordinating tasks and ensuring accurate and punctual treatment to achieve safe and effective patient care (Gilbert et al. 2010; McInnes et al. 2015). McInnes et al. (2015) propose three factors affecting collaboration and teamwork between hospital employees: 1) roles and responsibilities; 2) respect, trust, and communication; and 3) hierarchy, education, and liability. Understanding and respecting the roles of colleagues is important for effective collaboration (Besner et al. 2011; Sargeant et al. 2008), improving care as well as patient outcomes (Barrett et al. 2007; Brault et al. 2014). Trust in each other's work, respect, and proper communication are factors for favorable collaboration and performance improvements (Schadewaldt et al. 2013, 2014). Hierarchical structures limit the collaboration between nurses and physicians (Finlayson and Raymont 2012) and know-how for coordinating patient care is a premise for performance improvements (Sargeant et al. 2008). In addition to the three dimensions, it is important to distinguish between 1) organizational processes and 2) the medical treatment process as two separate kinds of collaboration (Lenz and Reichert 2007). Organizational processes help to coordinate the interaction between healthcare professionals and organizational units, whereas the medical treatment process focuses on the patient and diagnostic and therapeutic procedures.

There is a strong correlation between effective collaboration and team-building among health professionals and patients' medical treatment (Iya et al. 2017). Team-building positively influences clinical performance (Orledge et al. 2012; Tschan et al. 2006, 2009) as group development in hospitals facilitates team performance (Klein et al. 2009; Tannenbaum et al. 1992). Decisions made by teams with members who anticipate the needs of other collaborators (Iya et al. 2017) are superior to individual judgments and contain fewer mistakes (Salas et al. 2005; Smith-Jentsch et al. 2001). Teambuilding can be subdivided into 1) goal setting, 2) interpersonal relations, 3) problem solving, and 4) role clarification (Beer 1980; Buller and Bell 1986). Goal setting emphasizes the importance of goals that determine what the whole team strives to contribute (Leggat 2007; Salas et al. 1999), helps the team choose the correct approach, and affects the duration of and the effort expended in an action (Aga et al. 2016; Buller and Bell 1986). Interpersonal relations are unavoidable, and they involve increased supportiveness, confidence, and communication (Amos et al. 2005; Salas et al. 1999). Problem solving facilitates goal setting as every team member is involved in action planning to implement resolved solutions (Ezziane et al. 2012; Salas et al. 1999). Role clarification emphasizes the clear distribution of individual responsibilities and fixed roles within a team to reduce the probability of errors (Salas et al. 2005; Smith-Jentsch et al. 2001).

Collaboration and team-building are interdependent factors that facilitate frictionless processes in hospitals. On the one hand, incorrect or poor collaboration among employees has a negative effect on the team spirit. On the other hand, collaboration is weakened if team members do not work well together. The best results are therefore achieved by teams in which the atmosphere is perceived as positive and where collaboration among members is successful. However, there are common issues frequently experienced by clinicians in the context of collaboration and team-building:

1) Communication (insufficient - sufficient): Faulty information exchange is a major problem, not only between healthcare specialists and patients, but also among hospital employees (Kripalani et al. 2007). Insufficient 
communication among clinicians generally hinders accurate diagnosis and treatment, while sufficient communication is desirable for achieving a seamless care process (Balogh et al. 2015).

2) Responsibilities (opaque - clear): Physicians constantly face changing responsibilities, with a range of roles, and are frequently interrupted (Rosen et al. 2018; Wears and Berg 2005). It is not always possible to reach out for the most suitable experts in adequate time; the integration of multiple specialists is not straightforward, as medical information is not consistently available, possibly leading to different health-related conclusions.

3) Infrastructure (complex - simple): Treatment durations are extensive because clinicians' searches for information across multiple systems are time-consuming (Meier et al. 2014). Hospitals operate in complex clinical environments, with a wide range of systems containing different information; systems are not interconnected and operated by multiple professionals (Angst et al. 2010; Hanseth and Bygstad 2015). Simple and consistent presentation of medical data accelerates the treatment process.

4) Decisions (subjective - objective): Diagnosing and treating different diseases is strongly subjective, depending on individual experience and differing based on clinicians' emotions and mental states (Chang and Hsu 2009; Singh et al. 2020). This applies to experienced professionals and actors with different levels of expertise, e.g., young assistant doctors with limited clinical educations (Laurenzi et al. 2017; Singh et al. 2020). Even though clinicians try to derive objective decisions, they always act with subjective influence and own judgments.

Issues in the context of collaboration and team-building lead to insufficient medical decisions. Tackling these issues within hospitals presupposes the integration of suitable technologies such as CAs to improve team performance and thus the quality of care process and treatment of patients (Gopal et al. 2018; Klinker et al. 2019).

\section{Conversational agents as hybrid intelligence}

Research has focused on CAs in various disciplines (Brachten et al. 2018; Saffarizadeh et al. 2017; Seeber et al. 2018; Wünderlich and Paluch 2017), explaining them from different perspectives (Luger and Sellen 2016; von der Pütten et al. 2010). CAs can be classified along (Gnewuch et al. 2017) their primary mode of communication (how users interact with CAs, e.g., text-based or speech-based input) (Lee et al. 2009) and their main purpose (narrowed down to one task or used for a general context) (Nunamaker et al. 2011). However, there are overlaps in functionalities and alternative perspectives for classifications. CAs might be expanded to fit individual requirements or tasks (Chung et al. 2017), or text-based systems might use speech-to-text modules to convert human language (Gnewuch et al. 2017). Studies also distinguish between certain design characteristics as adaptivity (e.g., learning by analyzing and interpreting data and adjust to changed circumstances) or assistance domain (e.g., the context in which an agent provides appropriate assistance) (Knote et al. 2019). Furthermore, research identified additional effects on, for example, trust and its effects for collaboration where factors such as humanlikeness or self-presentation influence the willingness to collaborate with CAs (Følstad et al. 2018). There are various approaches to define CAs but without emerging a consistent solution. Luger and Sellen (2016) define CAs as "IS that enable the interaction with users via natural language" (p. 5287), Laumer et al. (2019) describe CAs as "text-based and voicebased automated dialog systems that can interact with a human user via natural language and answer questions on specific topics" (p. 2). We argue that these explanations are rather limiting the actual functionalities of CAs and thus define CAs as dialog systems simulating the behavior of humans via different modes of communication (e.g., written or spoken natural language, haptics, gestures, facial expressions, graphics), continuously learn and develop over time by analyzing and interpreting a given input combined with additional data sources for assisting with divergent tasks or execute them autonomously.

CAs receive increasing attention due to the constant progress of AI (Berg 2015; Spohrer and Banavar 2015). Building systems using underlying machine learning algorithms became more practicable (Knijnenburg and Willemsen 2016; Luger and Sellen 2016) as technical capabilities improved while costs decreased (Spohrer and Banavar 2015). Since CAs combine the complementary strengths of humans and AI (Kamar 2016), they represent a subset of hybrid intelligence (Dellermann et al. 2019a). Humans provide CAs with input to make them more effective, CAs provide humans with input to assist with decisions. Unlike regular IT or decision support systems, CAs are adaptive and behave reactively, proactively and autonomously (Meyer von Wolff et al. 2019). CAs continuously self-learn and develop over time by processing context information and user input (Mitchell et al. 2018). Furthermore, CAs handle tasks via dialogues, using written or spoken natural language, as well as interpreting gestures or facial expressions (Laumer et al. 2019; Nakano and Fukuhara 2012). CAs can also differentiate between and interpret the emotions of individuals within team communication (McDuff and Czerwinski 2018) and use different language styles to adapt to users (Gnewuch et al. 2020). These methods create a natural way of communication, in which users feel like talking to another human, thus indicating that CAs are inherently anthropomorphic (Feine et al. 2019; Hussain et al. 2019; Pfeuffer et al. 2019). Research further demonstrates that CAs are able to assist in decision making (Seeber et al. 2020b; Waizenegger et al. 2020) and are perceived as legitimate team members (Seeber et al. 2018). 
There is still a big difference in the level of capabilities CAs exhibit. Most CAs do not have a particular embodiment but are integrated into existing IS and interact with users via simple, natural language (Diederich et al. 2019). Currently deployed CAs are particularly useful for highly standardized processes or repetitive procedures, thus are rather domain-specific focusing on a narrow task (Batin et al. 2017; Knote et al. 2019). Results provided by CAs are generated according to an explicit pattern (Brachten et al. 2020; Mirbabaie et al. 2020). More complex contexts are still jointly solved with humans (Maedche et al. 2019). However, using the complementary strengths of CAs and humans to achieve complex goals while continuously learn from each other and develop over time, i.e., the concept of hybrid intelligence, yields in superior results (Dellermann et al. 2019b). Even though we are still far away from empathy-driven, creative robot teammates, we argue that integrating CAs as flexible communication partners into the daily routine of hospitals improves collaboration.

\section{Conversational agents in hospitals}

CAs in hospitals are beneficial in many areas but have mainly focused on the assistance of patients, e.g., in chronic disease self-care management (Kimani et al. 2016) or supporting diabetes patients in their daily routines (Shaked 2017), as systems are more successful performing health-related tasks compared to conventional interfaces (Bickmore et al. 2016). Besides, CAs are able to solve common problems in hospitals by enhancing collaboration and team-building among employees (Georgiadis 2011; Pynadath and Tambe 2003). Insufficient communication is countered through properly reported decision support based on medical information, excluding improper and incorrect communication among involved specialists. CAs are capable of adapting to different users with varying roles (Gnewuch et al. 2020; Pfeuffer et al. 2019) possibly leading to appropriate patient treatment and performance improvements in therapeutic processes (Schadewaldt et al. 2013, 2014). Opaque responsibilities are solved as CAs provide information about healthcare professionals' responsibilities (Traum et al. 2003). By continuously learning and developing, CAs act proactively and autonomously (Meyer von Wolff et al. 2019) enabling identifying rotating medical experts more easily and creating transparency (Bickmore et al. 2011; Kerly et al. 2007). Complex infrastructure is simplified since CAs assist in fulfilling tasks by providing the most suitable information and type of communication for their users (Laumer et al. 2019; Preece et al. 2017). CAs retrieve relevant medical information from multiple sources rapidly (Nasirian et al. 2017), merge information to present it in the manner most suited to their users thus reducing the handling time of medical duties to a minimum. Subjective decisions are excluded because CAs provide objective conclusions and evaluate patients' conditions based on medical facts from multiple years of experience (Mitchell et al. 2018). CAs do not depend on situations, emotions, or time of day (Gnewuch et al. 2017); they reach equal decisions when using identical medical data. An overview on common collaborative challenges clinicians frequently face in hospitals and the potential for CAs can be found in the appendix (Table 3).

We believe that CAs hold the potential to moderate collaborative challenges, for example, by providing communicative support through user-oriented interaction (Gnewuch et al. 2020; Pfeuffer et al. 2019) or delivering suitable medical information by learning and adapting to varying circumstances (Mitchell et al. 2018). With their unique capabilities, i.e., using social cues (Feine et al. 2019) and interpreting facial expressions, gestures and emotions (McDuff and Czerwinski 2018; Pfeuffer et al. 2019), CAs are also able to improve the overall team performance. Based on these assumptions, we derived a preliminary research model as depicted in Fig. 1.

CAs in hospitals are not just simple tools to perform narrow duties but can rather be seen as teammates collectively working with humans to achieve superior results (Dellermann et al. 2019b; Seeber et al. 2020a). However, there is still a lack in conceptualizing the challenges when introducing CAs in a team setting to improve collaboration in hospitals.

\section{Research approach}

\section{Systematic literature review}

Since CAs in hospitals are a relatively new research area, we argue that it will benefit from an accurate categorization transferring existing findings from related scientific streams. We thus decided to conduct a systematic approach for searching relevant literature to answer our research question. A SLR is suitable for tackling emerging issues, identifying knowledge about a topic including its gaps and supporting researchers in emphasizing their contribution of knowledge, by searching for relevant articles in scientific databases using keywords (Temple 2006; Webster and Watson 2002). Our research approach is divided into three steps. First, we use theoretical foundations, as suggested by McInnes et al. (2015), Lenz and Reichert (2007) and Salas et al. (1999), for classifying the existing research along the main characteristics of collaboration and team-building. The five categories on collaboration and the four categories on team-building served as a coherent conceptual pre-structure in which the literature was roughly categorized (Bem 1995). In the next step, we examined and compared the retrieved literature to identify correlations and similarities. Prior research was grouped into a categorization among the theoretical foundations. In the final step, we identified major challenges as well as implications for further research that should be pursued to successfully establish CAs for collaboration and team-building in hospitals. 
Fig. 1 Preliminary research model

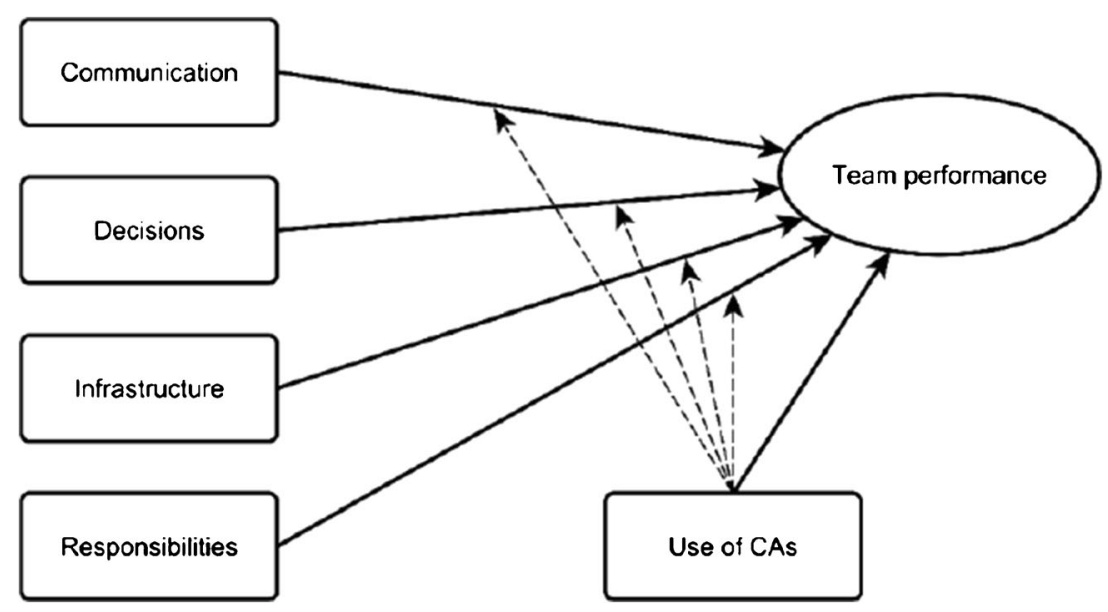

Following the literature review process (vom Brocke et al. 2009, 2015), we defined our research scope based on the taxonomy of literature reviews (Cooper 1988). We were interested in research focusing on different applications of CAs to adopt findings for their application in hospitals. The literature search considered all conference publications as well as journal articles from five bibliographic databases from the fields of computer science (ACM, IEEE, AISeL, SD, JSTOR). Less relevant sources, such as editorials, were excluded. To avoid overlooking relevant literature, we carried out a full-text and metadata search in every database, not limiting the search to metadata only as it cannot be guaranteed that search terms are contained in the metadata. Furthermore, not every abstract of each article is stored and accessible in the databases. Since there are various notations for the term "conversational agents" that are used interchangeably (Luger and Sellen 2016), we linked the most common ones within the search string "chat-bot", "chatbot" and "virtual agent". This expression was then combined with the terms "collaboration" and the different spellings of "team-building". We finally used the following query:

((“Conversational Agent" OR Chat-Bot OR Chatbot OR "Virtual Agent") AND (Collaboration OR Team-Building OR Teambuilding))

Parentheses are used to nest clauses or to group phrases. Separate statements are linked by Boolean expressions, and quotation marks are used to specify terms which must appear next to each other. After retrieving the literature, we carefully read the title, abstract, and keywords of each publication to determine its relevance according to our research question. We then categorized the literature according to the theoretical foundations about collaboration and team-building (for example statements and exemplary assignment, please see appendix, Table 5). Next, we performed a backward search to find additional papers by collecting all references of each paper's bibliography to other scientific publications. To determine the paper's relevance, we again read the title, abstract, and keywords followed by categorization according the theoretical foundations. As the last step, we conducted a forward search to further identify relevant literature, acknowledging all papers that had been retrieved in the database as well as in the backward search. Therefore, we were interested in articles that have been cited by other research after their initial publication. Once more, we read the title, abstract, and keywords and performed the categorization process as outlined above.

\section{Semi-structured expert interviews}

To highlight the consequences for the identified major challenges, we conducted semi-structured expert interviews with individuals having advanced knowledge in the investigated field of research (Meuser and Nagel 2009). We followed the approach of Meuser and Nagel (2009), who consider an open interview, supported by a prefixed guideline, as the most applicable way for retrieving valuable data while providing participants with enough room for elaborating their own subjective beliefs. We recruited hospital employees working in teams thus are able to judge from their own experience of collaboration and team-building. Furthermore, experts from the practice provided an unbiased picture of the actual situation and occurring problems. We acquired four physicians with diverse specialties and disciplines with varying training levels, enabling us to gain insights into various areas to broaden our view on collaboration and team-building in hospitals. Additionally, we carried out interviews with computer scientists experienced in the development and introduction of CAs ensuring that possible technical problems or restrictions are not overlooked. The interviews with the hospital employees were conducted via telephone, the computer scientists were consulted in face-to-face sessions and took place at their workplaces. All interviews took between 35 and 50 min and were recorded, analyzed, and, respecting data privacy protection, deleted once the evaluation was finished.

We developed a guideline following a consistent and systematic manner (Qu and Dumay 2011) with the following 
contents: 1) introduction and summary of the purpose of this research; 2) self-introduction of the expert; 3) applications of CAs in general and in hospitals; 4) application of CAs in hospitals to enhance collaboration and team-building including advantages, disadvantages, and challenges; and 5) conclusion of the interview (possibility for further questions or closing remarks). We analyzed the data according to theoretically aspects for a structured description of the collected information (Mayring 2014). The material is generalized and reduced during an abstraction process. Within the deductive procedure, the resulting categorical system of the extensive prior knowledge is structured and integrated into the major challenges (Mayring 2015). The findings were then integrated into the categories and supported by important aspects from the extant literature. Already gained insights can thus be underlined by important aspects of the analysis. The interview guideline as well as characteristics of the interviewees can be found in the appendix (Table 4 and 6).

\section{Findings}

\section{Overview}

The execution of SLR resulted in 44 relevant articles (31 via initial, 8 via backward and 5 via forward search). The classification illustrates the assignment of each relevant article to the theoretical foundations (cf. Table 1). The number of search results per scientific database is depicted in the appendix (Table 7).

In the following, we are summarizing the most relevant findings of our SLR regarding the theoretical foundations and explain how collaborative issues are mitigated by CAs. We could not identify any prototype or implementation facilitating collaboration or team-building among employees in hospitals. Most existing CAs contain a visual component (e.g., Bickmore et al. 2010; Hayashi and Ono 2013; Traum et al. 2003) or a text-based input (e.g., Bickmore et al. 2005; Nezhad et al. 2017; Tegos et al. 2012). Roles and responsibilities are improved when CAs allow users to define roles (Tegos et al. 2012) and know who is responsible for which duty (Traum et al. 2003). Enhancing respect, trust, and communication is achieved by the diffusion of reports (Kretzer et al. 2015) or by providing communication channels appropriate for a given task (Seeber et al. 2018). Hierarchy, education, and liability are improved when CAs use sensors to determine if a person is too dominant in a conversation (Nakano and Fukuhara 2012), classify tasks according to their importance (Nezhad et al. 2017) and enable clinicians to focus on relevant tasks (Bickmore et al. 2010, 2011). To achieve goal setting, CAs provide a quick overview of prioritized goals (Nezhad et al. 2017; Preece et al. 2017) and assist in goaldriven communication (Bickmore et al. 2011; Kerly et al. 2007). Regarding interpersonal relations, CAs distinguish between socio-emotional and task-related interactions (Prada and
Paiva 2009). Problem solving is achieved when CAs understand the overall goals, know how to reach them (Traum et al. 2003), assist with task fulfillment by providing the most suitable information (Preece et al. 2017), and help to overcome barriers (Bickmore et al. 2011). Role clarification is reached when CAs are aware of the different roles within a team (Tegos et al. 2012) and who is responsible for which duty (Traum et al. 2003).

CAs are beneficial for overcoming the collaborative issues experienced by clinicians. Communication is tailored to the individual characteristics and demands of each team member (Seeber et al. 2018), fostering willingness to collaborate and promoting information disclosure (Fitrianie et al. 2015; Shamekhi et al. 2018). CAs use various interaction styles like verbal and nonverbal communication or phrases and metaphors (Lim et al. 2011). Opaque responsibilities are tackled by CAs via sharing knowledge about clinicians' responsibilities and transparently express medical competencies (Hanna and Richards 2014; Nabeth et al. 2003). Additionally, CAs acquire information about responsible clinicians faster than humans because they can effortlessly handle large amounts of data while quickly adapting to changing demands (Preece et al. 2017). CAs simplify highly complex hospital infrastructures (Briggs et al. 2010) by fostering the presentation of information and linking disciplines enhancing information dissemination (Kerly et al. 2007; Seeber 2019). CAs combine knowledge from multiple sources and provide guidance on procedures and duties (Briggs et al. 2013; Seeber 2019). CAs enhance medical decisions as systems understand users' environments and evaluate patient data objectively, without any prejudices, while considering all medical information available (Bickmore et al. 2011; Siddike and Kohda 2018). With CAs, clinicians assess multidimensional situations and information that otherwise might be overlooked (Nezhad et al. 2017; Siddike et al. 2018). Furthermore, clinicians learn through agent-derived decisions as they receive adaptable feedback, fostering future decision-making (Nezhad et al. 2017) thus enhancing cognitive capabilities by raising awareness of options or pointing out specific patterns (Siddike et al. 2018).

\section{Major challenges}

\section{Audience and interdependency}

The notion of audience describes that CAs are used by multiple target groups. Hospital employees are not in the same age groups, differ in their expertise, have various professions, and work in different hierarchical structures and branches (Finlayson and Raymont 2012; Schadewaldt et al. 2014). One expert stated that "the age gap between some colleagues is simply extremely high. There are resident doctors who are in their mid-twenties and nurses who are in their late fifties" (E4). It is particularly relevant for hospitals to consider privileges in advance. For example, it needs to be validated if 
Table 1 Identified articles assigned to theoretical foundations 1) roles and responsibilities; 2) respect, trust, and communication; 3 ) hierarchy, education, and liability; 4)

organizational processes; 5) medical treatment process; 6) goal setting; 7) interpersonal relations; 8) problem solving; and 9) role clarification

\begin{tabular}{ll}
\hline Database & Article \\
& \\
\hline ACM & (Allen et al. 2002) \\
BS & (Bersot et al. 1998) \\
SD & (Bickmore and Giorgino 2006) \\
SD & (Bickmore et al. 2005) \\
SD & (Bickmore et al. 2010) \\
SD & (Bickmore et al. 2011) \\
AISeL & (Bittner et al. 2019a) \\
BS & (Bittner et al. 2019b) \\
BS & (Briggs et al. 2010) \\
BS & (Briggs et al. 2013) \\
FS & (Demetriadis et al. 2018) \\
AISeL & (Elson et al. 2018) \\
SD & (Fitrianie et al. 2015) \\
BS & (Gerhard et al. 2001) \\
ACM & (Hanna and Richards 2014) \\
IEEE & (Hayashi and Ono 2013) \\
BS & (Just et al. 2005) \\
SD & (Kerly et al. 2007) \\
BS & (Lim et al. 2011) \\
AISeL & (Nabeth et a. 2003)
\end{tabular}

AISeL

(Nabeth et al. 2003)

ACM (Nakano and Fukuhara 2012)

ACM (Nezhad et al. 2017)

BS (Ouldouali et al. 2017)

SD (Prada and Paiva 2009)

IEEE (Preece et al. 2017)

FS (Robb et al. 2015)

FS (Schmulian and Coetzee 2019)

SD (Seeber 2019)

AISeL (Seeber et al. 2018)

ACM (Shamekhi et al. 2018)

AISeL (Siddike and Kohda 2018)

AISeL (Siddike et al. 2018)

AISeL (Stoeckli et al. 2018)

AISeL (Tavanapour and Bittner 2018)

AISeL (Tavanapour et al. 2019)

IEEE (Tegos et al. 2012)

FS (Tegos and Demetriadis 2017)

IEEE (Tegos et al. 2012)

SD (Tegos et al. 2015)

ACM (Traum et al. 2003)

BS (Winkler et al. 2019)

ACM (Xiao et al. 2019)

FS (Zumbach et al. 2005)

Total numbers of articles
Collaboration

Team-building

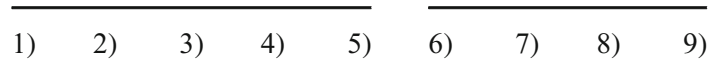

X

$\begin{array}{llll} & X & & X \\ & & X & \\ X & & X & X\end{array}$

X

$\mathrm{X}$

X

$\mathrm{X}$

X

X

$\mathrm{X}$

$\mathrm{X}$

$\mathrm{X}$

X

X

$\begin{array}{ll}X & X \\ & X \\ X & \end{array}$

$\begin{array}{cccccc} & \mathrm{X} & & & & \\ & \mathrm{X} & & & \mathrm{X} & \mathrm{X} \\ \mathrm{X} & & & \mathrm{X} & & \\ & & \mathrm{X} & & & \\ & & & \mathrm{X} & \end{array}$

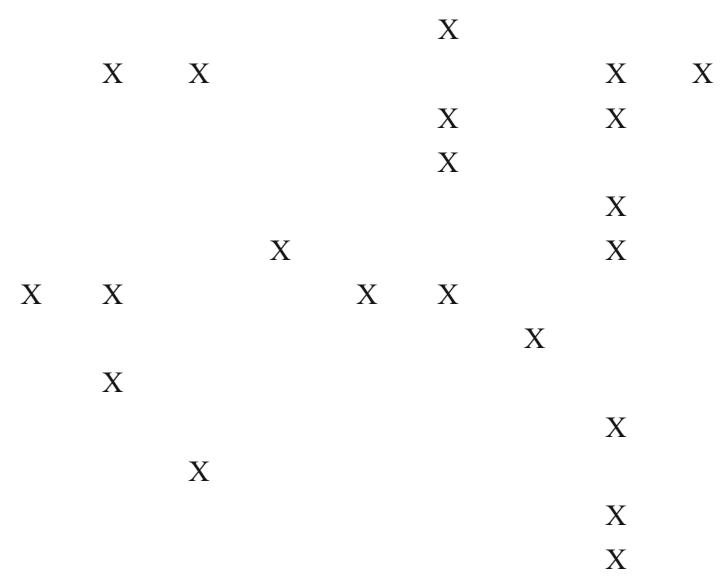

$\begin{array}{llllll}X & & & & \\ X & X & X & \\ & & & & X\end{array}$

\begin{tabular}{ccccccccc} 
& $X$ & $X$ & $X$ & & $X$ & $X$ & & \\
$X$ & & $X$ & & & & & $X$ & $X$ \\
& $X$ & $X$ & & $X$ & & & & \\
& & & & & & $X$ & $X$ & \\
& & & & & & $X$ & $X$ & \\
4 & 12 & 9 & 11 & 6 & 11 & 7 & 15 & 4 \\
\hline
\end{tabular}

patient-related data is accessible by every team member or whether there must be a differentiation in the hierarchical structures. CAs can adapt to existing hierarchy and responsibilities of hospital employees to improve collaboration. 
Interdependency characterizes the coexistence of employees and CAs and communication channels being appropriate for a given task and target audience (Seeber et al. 2018). Equivalent research shows that understanding the demographic characteristics is a critical factor (Andrews 2001, 2002). However, interdependency may also lead to tasks being performed in isolation or clinicians blindly relying on results provided by CAs.

\section{Connectivity and embodiment}

Connectivity and embodiment describe the interconnectedness of CAs and hospital departments and the preparation and presentation of patient-related data. Integrating different IS represents a main facet of supporting collaborative aspects (Kuziemsky et al. 2012). One expert emphasized that "information must be gathered from various data sources" (E6). A majority of IS applied in hospitals is tailored to the needs of each medical discipline and department with systems being highly customized. Not only departments but also IS are detached from each other (Lenz and Reichert 2007) but gaining shared understanding improves evaluation (Seeber 2019). CAs foster connection and sharing information (Marwan et al. 2016; Paul et al. 2016) by linking different systems and disciplines (Kerly et al. 2007) and assist with the documentation of the medical treatment process (Kerly et al. 2007). CAs also exist in different forms and can be utilized across a broad spectrum of situations. For example, CAs as text-based systems might be used in the outpatient clinic as hospital employees already use other systems with haptic input. Speechbased CAs could be applied within operating theatres as the sterile surrounding prohibits written input. The information presented by CAs can thus be oriented toward the patient, the disease and method of treatment.

\section{Trust and transparency}

Trust is a major challenge for technology to be accepted and utilized (Frick et al. 2020; Siddike and Kohda 2018; Söllner et al. 2016) and must be considered from two perspectives in this research: trust in the CA itself and trust in other humans. Trust in technology is vital for its usage but more difficult to achieve as it does not provide a human-to-human relationship (Lankton et al. 2015). Especially the initial trust, which is also established by the perceived level of competence (Seeber et al. 2018), determines future utilization (McKnight et al. 2002; Söllner et al. 2016). Trust in CAs is particularly relevant as decisions proposed by the system might have an impact on collaborative processes and the treatment of patients. There might be differences regarding the type of CAs further influenced by selected collaborators and their individual characteristics. Transparency causes discomfort but is crucial for building trust (Wünderlich and Paluch 2017). One expert underscored that "the application of such systems immediately makes information transparent, whereby errors in the treatment process become visible" (E6). This could lead to clinicians being less willing to disclose information to CAs which may even worsen collaboration. In hospitals, trust and transparency are particularly crucial as CAs do not only aid regarding the well-being of patients but disclose the entire diagnostic and treatment process to involved clinicians.

\section{Security, privacy, and ethics}

Security as subjective perception characterizes data authentication and authorization (Pavlou 2001), which includes the risk of violating users' (Yang et al. 2016) and patients' privacy. Security is necessary for adopting and utilizing CAs (Han and Yang 2018), influencing trusting beliefs (Eastlick et al. 2006; Kim 2008) and the willingness to share information (Dhami et al. 2013; Dinev and Hart 2006). Privacy is a subjective anticipation as well (Pavlou 2001). Using information discriminately leads discontinued use of systems (Culnan and Armstrong 1999). Violations are, for example, unauthorized collection or secondary use of information, improper access and errors in personal information (Smith et al. 1996). One interviewee clarified that "it is not only about patient information but about personal data of employees" (E5). Both security and privacy are urgent aspects when storing personal data of individuals (Abdelhamid et al. 2015; Kuckein et al. 2010). Due to the unique characteristics of CAs, humans might tend to share more personal information and sensitive data compared to other technologies. Any data leaks creating benefits for enterprises, for example, insurance companies predicting hospital costs based on disease patterns, resulting in disadvantages for patients, should be eliminated. Furthermore, CAs raise ethical concerns related to the application of technologies in hospitals (Bickmore et al. 2010), especially considering the collected information (Derrick et al. 2011). When comparing CAs to IS, the perception around ethical and moral issues varies (Bendel et al. 2021; Siau and Wang 2018b). Since the development of CAs is enabled by AI, results are not always comprehensible to humans (Hagras 2018). Dubious recommendations by CAs, e.g., requesting additional consultation from another clinical department for a patient belonging to certain ethnic group, may not be recognized.

\section{Future research agenda for IS}

Based on the findings from the SLR, enlightened by the semistructured expert interviews, the following research agenda points out which research needs to be pursued to successfully establish CAs in clinical environments affecting the quality of care process. Table 2 summarizes future research questions when applying CAs for collaboration and team-building in hospitals. 
Table 2 Future research questions for identified challenges

\begin{tabular}{|c|c|c|}
\hline Major challenge & Example research questions & References \\
\hline $\begin{array}{l}\text { Audience and } \\
\text { Interdependency }\end{array}$ & $\begin{array}{l}\text { How can CAs involve and coordinate different healthcare } \\
\text { professionals from multiple clinical departments? How do CAs } \\
\text { deal with various norms or specifications with heterogeneous } \\
\text { roles in hospitals? } \\
\text { How does the deployment of CAs in hospitals influence the } \\
\text { existing responsibilities and hierarchy of healthcare } \\
\text { professionals during collaboration? Which tasks can be carried } \\
\text { out by CAs for the different hospital areas to improve } \\
\text { collaboration within the medical treatment processes? } \\
\text { To what extent are CAs capable of promoting collaborative } \\
\text { decision making with other clinicians in hospitals? In what ways } \\
\text { do CAs help to ensure that health-related tasks are not per- } \\
\text { formed in isolation? } \\
\text { How can it be ensured that doctors or nurses do not blindly rely on } \\
\text { results derived by CAs for the collaborative treatment of } \\
\text { patients? How do physicians take responsibility for activities } \\
\text { and decisions proposed by CAs within collaborative processes? } \\
\text { Who is accountable for decisions given by CAs to clinicians in } \\
\text { hospitals? }\end{array}$ & $\begin{array}{l}\text { (Bersot et al. 1998; Bickmore et al. 2005, 2010; Gerhard et al. } \\
\text { 2001; Lim et al. 2011; Nabeth et al. 2003; Nezhad et al. 2017; } \\
\text { Preece et al. 2017; Seeber et al. 2018; Shamekhi et al. 2018; } \\
\text { Tegos et al. 2015, 2012) }\end{array}$ \\
\hline $\begin{array}{l}\text { Connectivity and } \\
\text { Embodiment }\end{array}$ & $\begin{array}{l}\text { How can CAs connect historically grown patient data and systems } \\
\text { that are already in use within hospitals, including their diverse } \\
\text { infrastructures, to drive collaborative decisions? } \\
\text { What medical information is captured through CAs? Which } \\
\text { information must be exchanged with other hospital IS (e.g., } \\
\text { electronic health records) to ensure flawless collaboration? } \\
\text { How can relevant medical information be identified for different } \\
\text { collaborators (e.g., hospital departments or clinical teams)? } \\
\text { Which information must be presented to healthcare specialists to } \\
\text { align with the patient's medical treatment and drive } \\
\text { collaboration? } \\
\text { What requirements must be placed on CAs to ensure their proper } \\
\text { functionality fostering collaboration in any hospital } \\
\text { environment, especially in sterile hygienic surroundings? How } \\
\text { can different types of CAs, e.g., text-based or speech-based, be } \\
\text { deployed for the varying hospital areas? }\end{array}$ & $\begin{array}{l}\text { (Briggs et al. 2010; Elson et al. 2018; Prada and Paiva 2009; } \\
\text { Seeber et al. 2018; Siddike et al. 2018; Tavanapour and Bittner } \\
\text { 2018) }\end{array}$ \\
\hline Trust and Transparency & $\begin{array}{l}\text { How are employees convinced of the objectives and advantages of } \\
\text { CAs to enhance collaboration in an environment where the } \\
\text { well-being of the patient is the primary concern? } \\
\text { Which collaboration team (e.g., hospital department or discipline) } \\
\text { shall use CAs initially? Where can CAs be introduced to } \\
\text { enhance collaboration without disrupting hospital procedures } \\
\text { and patient treatment? } \\
\text { How do collaborators cope with the transparency of their working } \\
\text { behavior initiated by CAs? To what extent are clinicians willing } \\
\text { to disclose information about working behaviors to CAs and } \\
\text { other hospital employees? } \\
\text { To what extent do clinicians perceive losing one's unique value or } \\
\text { their individual knowledge and control when CAs are applied } \\
\text { for collaborative purposes? }\end{array}$ & $\begin{array}{l}\text { (Allen et al. 2002; Bittner et al., 2019a; Hayashi 2018; Kerly et al. } \\
\text { 2007; Nabeth et al. 2003) }\end{array}$ \\
\hline $\begin{array}{l}\text { Security, Privacy, and } \\
\text { Ethics }\end{array}$ & $\begin{array}{l}\text { How can it be ensured that the data of patients as well as of hospital } \\
\text { collaborators are not retrieved by third parties? How can an } \\
\text { authorization concept for different healthcare collaborators for } \\
\text { the use of CAs be established? } \\
\text { To what extent are CAs able to determine objective characteristics } \\
\text { of patients? What medical basis is used to generate } \\
\text { recommendations to assist collaboration? How can } \\
\text { disadvantages for patients (e.g., as part of a certain group or } \\
\text { meet certain criteria) be excluded? } \\
\text { How can CAs learn from decisions made by healthcare } \\
\text { professionals? How can medical conclusions be generalized and } \\
\text { transferred to other collaborative settings in hospitals? } \\
\text { How can bias within the collaboration with CAs be recognized and } \\
\text { resolved by hospital employees? What could a control } \\
\text { mechanism by healthcare specialists look like? }\end{array}$ & (Bickmore et al. 2010; Just et al. 2005) \\
\hline
\end{tabular}

Audience and interdependency Technology needs to be understandable and usable to fulfill the user's needs (Lim et al. 2011; Norman 2013). Various interaction possibilities need to be offered to exploit the full potential (e.g., Bersot et al. 1998; Lim et al. 2011; Shamekhi et al. 2018). One participant pointed out that "older people prefer talking over typing" (E3). 
Systems must be able to adjust to users' different needs, personalities, attitudes, and moods (Andrews 2001, 2002; Seeber et al. 2018) but also consider the responsibilities and hierarchy of clinicians. CAs must be interesting, demanding and stimulating while encouraging employees to think for themselves (Nabeth et al. 2003). One expert mentioned that "the decisions of these systems should be questioned by employees" (E3). Systems should actively support individuals and perform repetitive tasks for which no cognitive abilities are needed (Nabeth et al. 2003). Since decision making in isolation frequently yields inferior results (Driscoll et al. 2015), CAs need to promote collaborative judgments with other clinicians avoiding decisions being performed in detachment. Establishing a relationship and tailoring the CA's behavior to the needs of the user is essential. However, this may lead to users becoming dependent. One respondent emphasized that this, "conveys a feeling of false security" (E2). This represents social loafing behavior, where a user in a group attempts less effort to achieve a goal than when working alone (Karau and Williams 1993). CAs completing almost every task might result in employees no longer identifying themselves with a decision and not questioning or taking responsibility for it. Individuals might even forget essential information as cognitive skills are becoming superfluous. One expert even had the idea that "critical decisions may be highlighted or need to be confirmed by a third person" (E1). Decisions in clinical environments need to be questioned and verified as diseases vary and evolve over time (Eigner et al. 2019; Zwaan and Singh 2015). Overall, we derived the following research proposition (RP):

RP1: We propose more research on how CAs enhance collaboration in hospitals by converging different user groups in varying clinical environments due to multiple professions, hierarchical structures, and expertise levels. CAs promote collaborative decision-making for diverse employees and their demographics, while rigorously monitoring inputs on treatment decisions. Furthermore, accountabilities and responsibilities of employees for using decisions proposed by CAs influence the performance of the collaborative diagnostic and therapeutic process.

Connectivity and embodiment Due to the diversity of IS in hospitals, data must be extracted and processed from multiple sources. Information is not always captured digitally, patient data is still recorded in handwritten files, making it difficult to gather information quickly. One expert complained that "handwritten files are sometimes simply not readable. If the nursing staff is handing over the files to the next shift, they are not where I expect them to be" (E1). Digital information is entered across multiple systems and users must switch between multiple applications (Lenz and Reichert 2007; Miner et al. 2016). The prerequisite of the treatment process being documented digitally (Kerly et al. 2007) ensures reaching the full potential of CAs. One expert underscored that "pendulum files will be dropped. We won't need inhouse mail anymore. All information of a patient is visible for every colleague" (E1). With the introduction of CAs, systems shall be linked with each other and information is only accessible via the CA (Kerly et al. 2007). However, information from systems of every department must be merged by CAs to help in locating information effectively (de Moraes Batista et al. 2009; Kassner et al. 2017; Xu and Topi 2017). It is not only relevant to process information from the applying hospital but also to have access to the entire course of the patient's illness, including information from other healthcare facilities. One expert explained that "something like a digital medical record must contain all of the patient's information" (E5). Furthermore, technical communication between multiple systems must be ensured using unified protocols and interfaces. The information presented by CAs should always be comprehensibly and oriented toward the patient and the disease as well as the method of treatment (Nabeth et al. 2003). It should also be noted that different departments need deviant information. To avoid confusing determination and presentation, CAs must possess both sufficient medical vocabulary and necessary information about a given task (Bittner et al. 2019a) and choose a suitable method of communication (Hayashi and Ono 2013). Furthermore, CAs must adapt to different environments. One expert described different interaction modes and surroundings: "there are areas in which a doctor is sterile and where a smartphone cannot be used" (E5). This led to our second proposition:

RP2: We propose more research on how CAs interconnect different hospital employees, departments, disciplines, and existing clinical information systems to expedite the collaboration among involved stakeholders and enhance medical data retrieval. CAs adapt to different clinicians and diverse clinical environments where medical data is tailored to each patient's treatment process to foster flawless collaboration.

Trust and transparency Users tend to have prejudices when starting to interact with technology (Sheridan and Hennessy 1984). One expert underscored, "in the beginning, there will be anxiety and fear of extra work or even disinterest" (E4). Without building trust in CAs, support with cognitive tasks is not provided thus decision making becomes more difficult (Briggs et al. 2010; Elson et al. 2018). Users having trust in CAs are more likely to be supported when making decisions (Frick et al. 2019; Elson et al. 2018). Interpersonal relations are unavoidable as they involve trust in other humans (Amos 
et al. 2005; Salas et al. 1999). The more physicians have trust in their colleagues, the more they acknowledge their expertise (McInnes et al. 2015; Schadewaldt et al. 2014). Trust in each other and the work affects the treatment process (McInnes et al. 2015; Schadewaldt et al. 2013, 2014). Lack of trust leads to clinicians questioning recommendations delays processes degrading collaboration (Briggs et al. 2010; Elson et al. 2018). To establish trust in CAs immediately, the intentions, benefits and possible obstacles should be explained and employees must be supported during the initiation process especially because users may have different experiences and previous knowledge (Frick et al. 2021). CAs should always have a detailed explanation on the focus of the task (Tavanapour and Bittner 2018). A step-by-step introduction is conceivable, not across all departments, but initially in one department or team, to identify potential errors and achieve a fully tested system. Utilization might be offered on a voluntary basis to recruit employees motivating or influencing their colleagues. One expert recommends introducing CAs "in an area where everyday tasks are executed that do not affect patients and where the speed is irrelevant" (E5). The application of CAs will increase the transparency of employees' roles and their tasks. One expert explained that "today, I have to make a call and beg for an appointment - and then the blame is always on others" (E1). Transparency causes discomfort but is crucial for trust-building (Wünderlich and Paluch 2017). The new transparency of both information and employees who use CAs could lead to a feeling of being monitored, losing one's unique value and knowledge. Not having trust yields in refusing or boycotting the system and hinders the willingness to disclose information. One interviewee mentioned that "transparency enables CAs to detect failures in the treatment process" (E6). However, alleviating related negative consequences is achieved when "good results and fast performances are communicated, rewarded, and made visible to other employees" and further "through the transparency of good work, a new team spirit can be created" (E3). This led to our third research proposition:

RP3: We propose more research on how CAs assist in building clinicians' trust in other hospital employees and their abilities across interdepartmental boundaries, as well as in the technology itself, to generate advantages that will directly and indirectly affect clinicians and patients. CAs initiate transparency between collaborators, including their working behaviors and newfound clarity in the therapeutic process. Resistance factors, loss of autonomy, and the importance of individual knowledge when using CAs affect willingness to disclose information about medical decisions.
Security, privacy, and ethics There shouldn't be any misuse by third parties and no information published without the consent of the person concerned (Just et al. 2005). This applies to the personal information of patients and employees. One interviewee summed up "the protection of data must be guaranteed at all times. There is sensitive information such as disease pictures or life expectancy" (E2). Information must be carefully protected with the highest security standards. Any data leaks or the disclosure of information without the consent of involved individuals might have serious consequences. There are also moral issues related to the application of CAs (Bickmore et al. 2010) as they are still being trained by humans and might contain unintended bias (Rothenberger et al. 2019; Siau and Wang 2018a) or even aim at changing the user's behavior (Bickmore et al. 2010) and initial perceptions (Elson et al. 2018). One expert explained that "such a system must not make unethical or morally reprehensible decisions" and delineated "an example would be to remove a patient from a planned operation based on false, incomplete, or purely objective information" (E1). Based on decisions derived by physicians, CAs might learn prejudices. Even though this may be evident from the data, it is questionable whether this should lead to disadvantages for patients belonging to a certain group or meeting particular criteria. CAs objectively evaluate the patient's condition but cannot obtain subjective impressions. When making difficult choices, a physician is ultimately responsible for the decision and must be aware of moral and ethical implications (Seymour et al. 2018). Decisions shall therefore be able to be overwritten and CAs need to learn and apply new knowledge to other circumstances. The above aspects lead to our final proposition:

RP4: We propose more research on how CAs ensure secure data collection, information presentation by clinicians, and storage of patients' medical data, addressing how unauthorized access is prevented. Furthermore, we demand determining the extent to which morally and ethically unacceptable results are identified by clinicians and CAs to avoid potential safety hazards for patients and what a control mechanism could look like. CAs and hospital collaborators learn from decisions and medical conclusions to generalize and adapt to other collaborative settings in clinical environments.

Drawing from the major challenges identified when applying CAs for collaboration and team-building in hospitals, and combining these with our propositions for future in-depth research, we designed our final research model (cf. Fig. 2). We argue that the major challenges, including their various factors, directly impact the extent to which CAs are used in hospitals. Future research should not only consider the individual research questions as outlined in the agenda, but also 
Fig. 2 Final research model

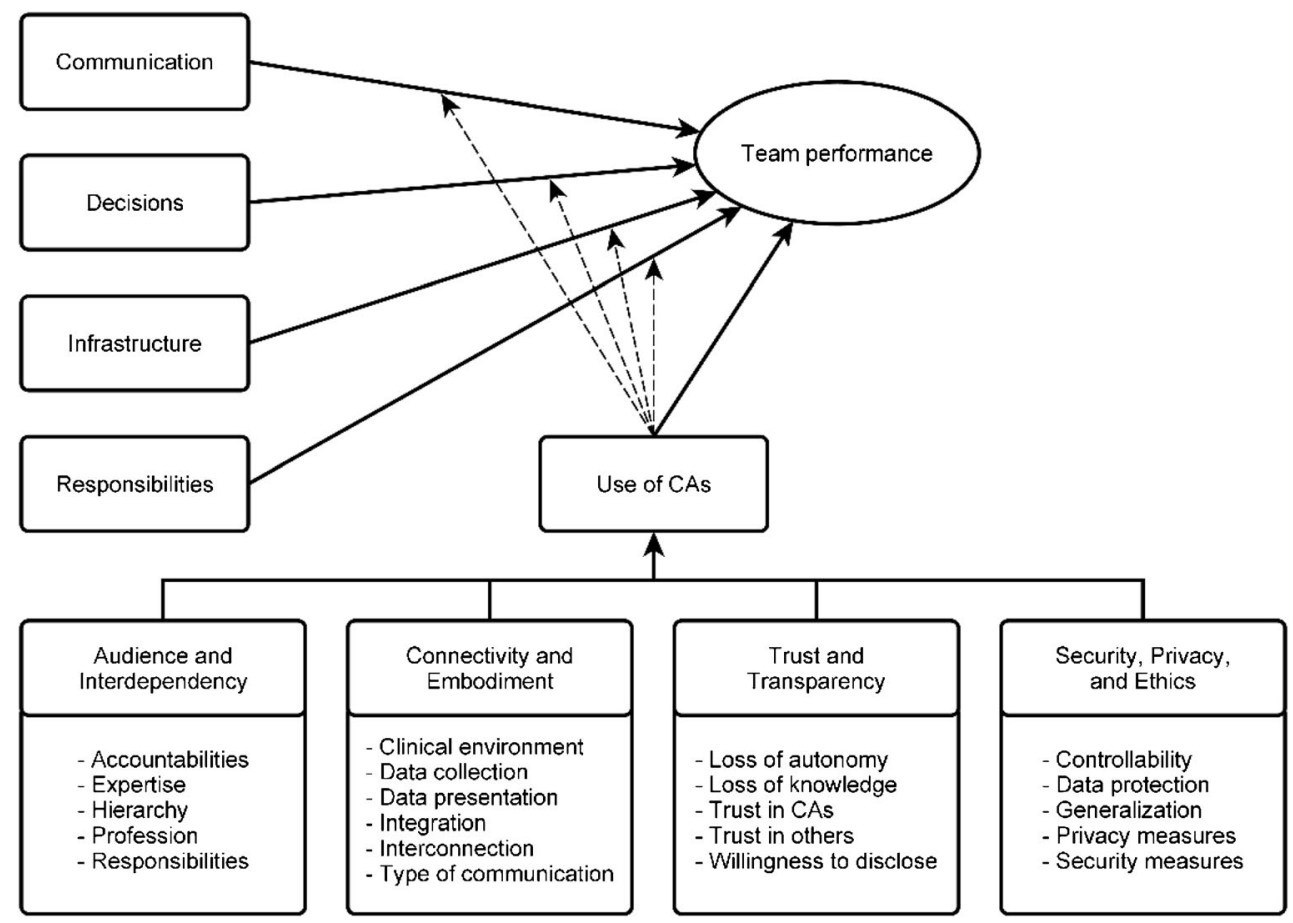

examine the individual influencing factors of each major challenge and their relationships, which impact the use of CAs for enhancing team performance in hospitals.

Finally, it should be noted that these challenges also influence each other; for example, unethical decisions or the type of CA inevitably influences trust in the system. The results presented above show that there are several questions that must be tackled in future research. However, this research advocates that CAs as a subset of hybrid intelligence are capable of improving collaboration and team-building, and thus, the quality of healthcare services and team performance in hospitals.

\section{Conclusion and limitations}

Drawing from the literature about collaboration and team-building, enlightened by expert interviews, this article contributes to theoretical foundations by presenting challenges that need to be faced when applying CAs in hospitals and pointing out areas where future in-depth investigations are needed. We answer our research question by demonstrating how the interaction between humans and CAs affects the quality of care process and which factors impact the use of CAs for enhancing team performance. The conclusions are relevant for researchers as the overview of challenges is helpful in considering difficulties before the actual introduction of
CAs. Practitioners understand the extent to which CAs improve collaboration and team-building in hospitals.

This research is not free of limitations. There are various notations for the term CAs that are used interchangeably in research and practice. However, to narrow down the scope of this study, we linked the most common terms within the SLR. Even though the identified articles provide a sufficient foundation for the research agenda, we may have missed the retrieval of relevant literature providing additional findings. We further present a small group of experts who cover a limited fraction of knowledge. Although we conducted interviews with both physicians and computer scientists, further stakeholders should be considered in future research to retrieve a broader picture, i.e., other hospital employees such as nursing staff or surgical assistants or computer scientists working in the healthcare sector.

Besides the research agenda, studies should also focus on deviant perspectives. What further challenges need to be considered when CAs are applied in hospitals? What other benefits besides collaboration and team-building can be achieved? How must a system be designed to be effective and efficient and to adapt to different users in hospitals? Our future research aims at identifying exact use cases where systems can be used to improve collaboration and team-building in hospitals. Therefore, we are going to observe different clinicians in several hospitals over a longer period to grasp the phenomenon of how CAs concretely support collaboration. 


\section{Appendix}

\section{Collaborative challenges in hospitals}

Table 3 Challenges and potential for CAs improving collaboration in hospitals

Challenges in hospital

Communication among clinicians (e.g., miscommunication for medical dispensing).

Responsibilities of clinicians as patients are treated by multiple specialists with different medical information.

Infrastructure as multiple systems for various purposes exist, containing different information; interconnected and operated by various users.

Decisions are depending on individual experiences, emotions and mental state of clinicians.

\section{Potential for CAs}

Communicative support (e.g., among different hierarchical structures or disciplines)

Performance improvements in diagnostic and therapeutic process

Stress-free work environment

Enhancing team atmosphere and cohesion

Transparent information on clinicians' duties

Fast retrieval of responsible healthcare specialists

Simplified goal-driven communication and collaboration

Providing suitable information for users

Merging data from multiple origins

Fast retrieval of medical information

Minimizing task duration

Simplified reporting of information

Transparent diagnostic and treatment process

Objective and equal evaluation of patient data

Non-prejudices decisions (e.g., objective conclusion based on medical facts)

Independent decisions regardless of time or mental state
Example references

(Balogh et al. 2015; Kanjanarat et al. 2003;

Kripalani et al. 2007; McInnes et al. 2015;

Schadewaldt et al. 2013, 2014)

(Bickmore et al. 2011; Kerly et al. 2007; Rosen et al. 2018; Traum et al. 2003; Wears and Berg 2005)

(Angst et al. 2010; Hanseth and Bygstad 2015; Meier et al. 2014; Nasirian et al. 2017; Preece et al. 2017)

(Chang and Hsu 2009; Gnewuch et al. 2017; Laurenzi et al. 2017; Seeber et al. 2019; Singh et al. 2020)

\section{Interview guideline}

Table 4 Interview guideline (German interview questions have been translated into English)

\begin{tabular}{|c|c|c|}
\hline Phase & Research goal & Questions \\
\hline Introduction & $\begin{array}{l}\text { Welcoming the interviewee and providing } \\
\text { general information about the research and brief } \\
\text { introduction to the topic. }\end{array}$ & - \\
\hline Demographic data & $\begin{array}{l}\text { Getting an understanding of the interviewee } \\
\text { including position within the } \\
\text { hospital/organization and the areas of responsi- } \\
\text { bility. }\end{array}$ & $\begin{array}{l}\text { a) Could you please introduce yourself? } \\
\text { b) What is your current position in your hospital/organizations and what are your } \\
\text { responsibilities? }\end{array}$ \\
\hline Application of CAs & $\begin{array}{l}\text { Awareness of previous experiences with CAs and } \\
\text { applications within in general and in hospitals. }\end{array}$ & $\begin{array}{l}\text { a) What do you associate with the term "Conversational Agent" and which } \\
\text { application areas are you familiar with? } \\
\text { b) Which areas of application are known to you in hospitals? } \\
\text { Afterwards the researchers provide an explanation of CAs and current examples } \\
\text { to assume the same knowledge among all participants. }\end{array}$ \\
\hline $\begin{array}{l}\text { CAs in context of } \\
\text { collaboration and } \\
\text { team-building }\end{array}$ & $\begin{array}{l}\text { Possible applications of CAs in hospitals, } \\
\text { especially regarding to collaboration and } \\
\text { team-building considering the theoretical foun- } \\
\text { dations. }\end{array}$ & $\begin{array}{l}\text { a) Can you imagine how CAs can be applied to improve collaboration and } \\
\text { team-building in hospitals? } \\
\text { b) What might be the advantages and disadvantages when introducing CAs? } \\
\text { c) How important is the understanding of the role and responsibilities for you } \\
\text { and your colleagues? (roles and responsibilities) } \\
\text { d) What role does respect, trust and communication play, especially with } \\
\text { colleagues? (respect, trust and communication) } \\
\text { e) How important is the hierarchy and education of hospital employees? } \\
\text { (hierarchy, education and liability) } \\
\text { f) How can the organizational process or the medical treatment of patients be } \\
\text { affected? (organizational processes and medical treatment process) } \\
\text { g) How can the achievement of goals and problem solving be supported? (goal } \\
\text { settings and problem solving) } \\
\text { h) How important are interpersonal relations and the understanding of one's own } \\
\text { role? (interpersonal relations and role clarification) }\end{array}$ \\
\hline Finish & $\begin{array}{l}\text { Debriefing of the interviewee and explanation of } \\
\text { the research background. }\end{array}$ & - \\
\hline
\end{tabular}




\section{Exemplary Assignments}

Table 5 Example statements and exemplary assignment to a category

\begin{tabular}{|c|c|c|}
\hline & Category & Sample statement \\
\hline \multirow[t]{5}{*}{ Collaboration } & $\begin{array}{l}\text { 1) roles and } \\
\text { responsibilities }\end{array}$ & $\begin{array}{l}\text { "the role of the system is primarily to provide information to } \\
\text { enable the user to make informed choices" (T. W. Bickmore } \\
\text { et al. 2010, p. 280) }\end{array}$ \\
\hline & $\begin{array}{l}\text { 2) respect, trust, and } \\
\text { communication }\end{array}$ & $\begin{array}{l}\text { "After having defined different interaction modalities for } \\
\text { communication with the Sprytes, we took into account the } \\
\text { right assignment of the modalities to the different users in } \\
\text { order to increase their engagement as well as collaboration." } \\
\text { (Lim et al. 2011, p. 227) }\end{array}$ \\
\hline & $\begin{array}{l}\text { 3) hierarchy, education, } \\
\text { and liability }\end{array}$ & $\begin{array}{l}\text { "Teamwork in STEAM is based on the agents' building up a } \\
\text { hierarchy of joint intentions and monitoring other members' } \\
\text { and team's performances and reorganizing the hierarchy } \\
\text { when necessary" (Prada and Paiva 2009, p. 82) }\end{array}$ \\
\hline & $\begin{array}{l}\text { 4) organizational } \\
\text { processes }\end{array}$ & $\begin{array}{l}\text { "Indeed, what the users ultimately need are not so much tools } \\
\text { that will be able to process more efficiently an even larger } \\
\text { amount of information, but rather 'smarter' tools that are able } \\
\text { to support more effectively the knowledge related processes } \\
\text { that are inherently connected to their work, and the operations } \\
\text { of organizations." (Nabeth et al. 2003, p. 70) }\end{array}$ \\
\hline & $\begin{array}{l}\text { 5) medical treatment } \\
\text { process }\end{array}$ & $\begin{array}{l}\text { "These examples are motivated by interactions we have } \\
\text { observed in a medical advisor domain in which the system } \\
\text { acts to help a person manage their medications." (Allen et al. } \\
\text { 2002, p. } 778 \text { ) }\end{array}$ \\
\hline \multirow[t]{4}{*}{ Team-building } & 6) goal setting & $\begin{array}{l}\text { "The working alliance has three sub-components: a goal } \\
\text { component, reflecting the degree to which the helper and } \\
\text { client agree on the goals of the therapy" (T. Bickmore et al. } \\
\text { 2005, p. 22) }\end{array}$ \\
\hline & 7) interpersonal relations & $\begin{array}{l}\text { "This initial evaluation of a relational agent in a health behavior } \\
\text { change intervention indicates that patients are generally } \\
\text { receptive to the technology and respond in ways analogous to } \\
\text { how we would expect them to respond when the same } \\
\text { emotional and relational communication behaviors are used } \\
\text { by human health providers." (T. Bickmore et al. 2005, p. 28) }\end{array}$ \\
\hline & 8) problem solving & $\begin{array}{l}\text { "Our approach to the later stages of change involves long-term } \\
\text { and short-term goal setting negotiation, positive reinforce- } \\
\text { ment when goals are met and 'problem solving' to overcome } \\
\text { barriers when goals are not met." (T. Bickmore et al. 2011, p. } \\
\text { 189) }\end{array}$ \\
\hline & 9) role clarification & $\begin{array}{l}\text { "Agents can be given different personalities and different roles } \\
\text { (e.g. tutor, coach, learning companion or opponent), which } \\
\text { may increase the interest of the students." (Tegos et al. 2011, } \\
\text { p. 162) }\end{array}$ \\
\hline
\end{tabular}




\section{Experts' characteristics}

Table 6 Characteristics of the interviewees

\begin{tabular}{llllllll}
\hline \# & Gender & Age & Tenure (years) & Position & Specialty & Discipline & Hospital \\
E1 & Female & 30 & 1 & Resident doctor & Surgeon & Cranio-maxillofacial surgery & University Hospital of Duesseldorf \\
E2 & Female & 30 & 3 & Resident doctor & Gynecologist & Obstetric care & University Hospital of Frankfurt \\
E3 & Male & 34 & 5 & Attending physician & Rheumatologist & Rheumatology & University Hospital of Munich \\
E4 & Male & 65 & 30 & Chief physician & Anesthetist & Anesthesia & Saint Francis Hospital Muenster \\
\# & Gender & Age & Tenure (years) & Position & Branch & \\
E5 & Male & 28 & 8 & Full Stack Developer & IT Management and Consulting & \\
E6 & Male & 32 & 10 & Head of Data Analytics & IT Service Provider \\
\hline
\end{tabular}

\section{Search results}

Table 7 Number of search results per scientific database (articles up until October 2019)

\begin{tabular}{lll}
\hline Database & No. of results & No. of relevant results \\
\hline ACM (Association for Computing Machinery) & 173 & 7 \\
AISeL (Association for Information Systems Electronic Library) & 140 & 10 \\
IEEE (Institute of Electrical and Electronics Engineers) & 42 & 4 \\
JSTOR (Journal Storage) & 55 & 0 \\
SD (ScienceDirect) & 399 & 10 \\
Backward search & 18 & 8 \\
Forward search & 14 & 5 \\
Total numbers of articles & 841 & 44 \\
\hline
\end{tabular}

Funding Open Access funding enabled and organized by Projekt DEAL.

Open Access This article is licensed under a Creative Commons Attribution 4.0 International License, which permits use, sharing, adaptation, distribution and reproduction in any medium or format, as long as you give appropriate credit to the original author(s) and the source, provide a link to the Creative Commons licence, and indicate if changes were made. The images or other third party material in this article are included in the article's Creative Commons licence, unless indicated otherwise in a credit line to the material. If material is not included in the article's Creative Commons licence and your intended use is not permitted by statutory regulation or exceeds the permitted use, you will need to obtain permission directly from the copyright holder. To view a copy of this licence, visit http://creativecommons.org/licenses/by/4.0/.

\section{References}

Aanestad, M., \& Vassilakopoulou, P. (2019). Collaborative innovation in healthcare: Boundary resources for peripheral actors. Proceedings of the 40th International Conference on Information Systems (ICIS), Munich, Germany. https://aisel.aisnet.org/icis2019/is health/is health/24
Abdelhamid, M., Sharman, R., \& Bezawada, R. (2015). Better patient privacy protection with better patient empowerment about consent in health information exchanges. Proceedings of WISP 2015, Siena, Italy. https://aisel.aisnet.org/wisp2015/14

Aga, D. A., Noorderhaven, N., \& Vallejo, B. (2016). Transformational leadership and project success: The mediating role of team-building. International Journal of Project Management, 34(5), 806-818. https://doi.org/10.1016/j.ijproman.2016.02.012 .

Allen, J., Blaylock, N., \& Ferguson, G. (2002). A problem solving model for collaborative agents. Proceedings of the first international joint conference on autonomous agents and multiagent systems, 774 781. https://doi.org/10.1145/544862.544923 .

Amos, M. A., Hu, J., \& Herrick, C. A. (2005). The impact of team building on communication and job satisfaction of nursing staff. Journal for Nurses in Staff Development (JNSD), 21(1), 10-16. https://doi.org/10.1097/00124645-200501000-00003 .

Andrews, D. (2001). Considerations in the development of commercially based online communities. Proceedings of the 7th Americas Conference on Information Systems (AMCIS), Boston, USA. https://aisel.aisnet.org/amcis2001/295

Andrews, D. (2002). Audience-specific online community design. Communications of the ACM, 45(4), 64-68. https://doi.org/10. $1145 / 505248.505275$

Angst, C. M., Agarwal, R., Sambamurthy, V., \& Kelley, K. (2010). Social contagion and information technology diffusion: The 
adoption of electronic medical records in U.S. hospitals. Management Science, 56(8), 1219-1241. https://doi.org/10.1287/ mnsc.1100.1183.

Atherton, P. J., Smith, T., Singh, J. A., Huntington, J., Diekmann, B. B., Huschka, M., \& Sloan, J. A. (2013). The relation between cancer patient treatment decision-making roles and quality of life. Cancer, 119(12), 2342-2349. https://doi.org/10.1002/cncr.28046 .

Babiker, A., El Husseini, M., Al Nemri, A., Al Frayh, A., Al Juryyan, N., Faki, M. O., Assiri, A., Al Saadi, M., Shaikh, F., \& Al Zamil, F. (2014). Health care professional development: Working as a team to improve patient care. Sudanese Journal of Paediatrics, 14(2), 9-16.

Balogh, E. P., Miller, B. T., \& R., B. (2015). Improving diagnosis in health care. Washington, DC: The National Academies Press. https://doi.org/10.17226/21794 .

Barrett, J., Curran, V., Glynn, L., \& Godwin, M. (2007). CHRSF synthesis: Interprofessional collaboration and quality primary healthcare. In Canadian Health Services Research Foundation (Issue December).

Batin, M., Turchin, A., Markov, S., Zhila, A., \& Denkenberger, D. (2017). Artificial intelligence in life extension: From deep learning to Superintelligence. Informatica, 41, 401-417.

Bear, A., \& Knobe, J. (2016). Normality: Part descriptive, part prescriptive. Cognition, 167, 25-37. https://doi.org/10.1016/j.cognition. 2016.10.024 .

Beer, M. (1980). Organization change and development: a systems view. Santa Monica, Calif:: Goodyear Publishing Company.

Bell, D. E. (1989). Decision making: Descriptive, normative, and prescriptive interactions. Cambridge University Press.

Bem, D. J. (1995). Writing a review article for psychological bulletin. Psychological Bulletin, 118(2), 172-177. https://doi.org/10.1037/ 0033-2909.118.2.172

Berg, M. M. (2015). NADIA: A simplified approach towards the development of natural dialogue systems. In C. Biemann, S. Handschuh, A. Freitas, F. Meziane, \& E. Métais (Eds.), Natural language processing and information systems (1st ed., pp. 144-150). Springer International Publishing. https://doi.org/10.1007/978-3-319-19581$0 \_12$.

Bersot, O., El Guedj, P.-O., Godéreaux, C., \& Nugues, P. (1998). A conversational agent to help navigation and collaboration in virtual worlds. Virtual Reality, 3(1), 71-82. https://doi.org/10.1007/ BF01409799.

Besner, J., Drummond, N., Oelke, R., McKim, R., \& Carter, J. (2011). Optimizing the practice of registered nurses in the context of an interprofessional team in primary care. Health Systems and Workforce Research Unit, Alberta Health Services.

Bickmore, T., \& Giorgino, T. (2006). Health dialog systems for patients and consumers. Journal of Biomedical Informatics, 39(5), 556-571. https://doi.org/10.1016/j.jbi.2005.12.004 .

Bickmore, T., Gruber, A., \& Picard, R. (2005). Establishing the computer-patient working alliance in automated health behavior change interventions. Patient Education and Counseling, 59(1), 21-30. https://doi.org/10.1016/j.pec.2004.09.008 .

Bickmore, T., Puskar, K., Schlenk, E., Pfeifer, L., \& Sereika, S. (2010). Maintaining reality: Relational agents for antipsychotic medication adherence. Interacting with Computers, 22(4), 276-288. https://doi. org/10.1016/j.intcom.2010.02.001 .

Bickmore, T., Schulman, D., \& Sidner, C. (2011). A reusable framework for health counseling dialogue systems based on a behavioral medicine ontology. Journal of Biomedical Informatics, 44(2), 183-197. https://doi.org/10.1016/j.jbi.2010.12.006 .

Bickmore, T., Utami, D., Matsuyama, R., \& Paasche-Orlow, M. K. (2016). Improving access to online health information with conversational agents: A randomized controlled experiment. Journal of Medical Internet Research, 18(1), e1. https://doi.org/10.2196/jmir. 5239 .
Bittner, E., Küstermann, G., \& Tratzky, C. (2019a). The facilitator is a bot: Towards a conversational agent for facilitating idea elaboration on idea platforms. Proceedings of the 27th European Conference on Information Systems (ECIS), Stockholm \& Uppsala, Sweden. https:// aisel.aisnet.org/ecis2019 rp/166

Bittner, E., Oeste-Reiß, S., \& Leimeister, J. M. (2019b). Where is the bot in our team? Toward a taxonomy of design option combinations for conversational agents in collaborative work. Hawaii International Conference on System Sciences (HICCS). https://doi.org/10.24251/ hicss.2019.035.

Brachten, F., Brünker, F., Frick, N. R. J., Ross, B., \& Stieglitz, S. (2020). On the ability of virtual agents to decrease cognitive load: An experimental study. Information Systems and E-Business Management., 18, 187-207. https://doi.org/10.1007/s10257-02000471-7.

Brachten, F., Mirbabaie, M., Stieglitz, S., Berger, O., Bludau, S. \& Schrickel, K. (2018). Threat or Opportunity? - Examining Social Bots in Social Media Crisis Communication. Proceedings of the 29th Australasian Conference on Information Systems (ACIS), Sydney, Australia.

Brault, I., Kilpatrick, K., Amour, D., Contandriopoulos, D., Chouinard, V., Dubois, C., Perroux, M., \& Beaulieu, M. (2014). Role clarification processes for better integration of nurse practitioners into primary healthcare teams : A multiple-case study. Nursing Research and Practice, 2014, 9. https://doi.org/10.1155/2014/170514 -9.

Brendel, Alfred, Mirbabaie, Milad, Lembcke, Tim-Benjamin \& Hofeditz, Lennart (2021). Ethical Management of Artificial Intelligence. Sustainability, 13(4). https://doi.org/10.3390/su13041974 .

Briggs, R. O., Kolfschoten, G. L., de Vreede, G.-J., Albrecht, C. C., \& Lukosch, S. G. (2010). Facilitator in a box: Computer assisted collaboration engineering and process support Systems for Rapid Development of collaborative applications for high-value tasks. 43rd Hawaii International Conference on System Sciences (HICSS), 1-10. https://doi.org/10.1109/HICSS.2010.206

Briggs, R. O., Kolfschoten, G. L., de Vreede, G.-J., Lukosch, S., \& Albrecht, C. C. (2013). Facilitator-in-a-box: Process support applications to help practitioners realize the potential of collaboration technology. Journal of Management Information Systems, 29(4), 159-194. https://doi.org/10.2753/MIS0742-1222290406 .

Buller, P. F., \& Bell, C. H. (1986). Effects of team building and goal setting on productivity: A field experiment. Academy of Management Journal, 29(2), 305-328. https://doi.org/10.2307/ 256190 .

Chang, C.-L., \& Hsu, M.-Y. (2009). The study that applies artificial intelligence and logistic regression for assistance in differential diagnostic of pancreatic cancer. Expert Systems with Applications, 36(7), 10663-10672. https://doi.org/10.1016/j.eswa.2009.02.046 .

Charette, R. (2006). EHRs: Electronic health records or exceptional hidden risks? Communications of the ACM, 49(6), 120. https://doi.org/ 10.1145/1132469.1132495

Chung, H., Lorga, M., Voas, J., \& Lee, S. (2017). Alexa, can I trust you? IEEE Computer Society, 50(9), 100-104. https://doi.org/10.1109/ MC.2017.3571053 .

Cooper, H. M. (1988). Organizing knowledge syntheses: A taxonomy of literature reviews. Knowledge in Society, 1(1), 104-126. https://doi. org/10.1007/BF03177550 .

Culnan, M., \& Armstrong, P. (1999). Information privacy concerns, procedural fairness, and impersonal trust: An empirical investigation. Organization Science, 10(1), 104-115. https://doi.org/10.1287/orsc. 10.1.104.

de Moraes Batista, A. F., das Gracas Bruno Marietto, M., de O Barbosa, G. C., dos Santos Franca, R., \& Kobayashi, G. (2009). Multi-agent systems to build a computational middleware: A chatterbot case study. International Conference for Internet Technology and Secured Transactions, (ICITST), 1-2. https://doi.org/10.1109/ ICITST.2009.5402586 . 
Dellermann, D., Lipusch, N., Ebel, P., \& Leimeister, J. (2018). Design principles for a hybrid intelligence decision support system for business model validation. Electronic Markets, 29, 1-19. https://doi.org/ 10.1007/s12525-018-0309-2 .

Dellermann, D., Calma, A., Lipusch, N., Weber, T., Weigel, S., \& Ebel, P. (2019a). The future of human-AI collaboration: A taxonomy of design knowledge for hybrid intelligence systems. Hawaii International Conference on System Sciences (HICSS). https://doi. org/10.24251/HICSS.2019.034

Dellermann, D., Ebel, P., Söllner, M., \& Leimeister, J. M. (2019b). Hybrid intelligence. Business \& Information Systems Engineering, 61(5), 637-643. https://doi.org/10.1007/s12599-019-00595-2 .

Demetriadis, S., Tegos, S., Psathas, G., Tsiatsos, T., Weinberger, A., Caballe, S., Dimitriadis, Y., Sanchez, E. G., Papadopoulos, P. M., \& Karakostas, A. (2018). Conversational agents as group-teacher interaction mediators in MOOCs. Learning With MOOCS, 588438, 43-46. https://doi.org/10.1109/LWMOOCS.2018. 8534686

Derrick, D. C., Jenkins, J. L., \& Nunamaker, J. F. (2011). Design principles for special purpose, embodied, conversational intelligence with environmental sensors (SPECIES) agents. AIS Transactions on Human-Computer Interaction, 3(2), 62-81.

Dhami, A., Agarwal, N., Chakraborty, T. K., Singh, B. P., \& Minj, J. (2013). Impact of trust, security and privacy concerns in social networking: An exploratory study to understand the pattern of information revelation in Facebook. 3rd IEEE International Advance Computing Conference (IACC), 465-469. https://doi.org/10.1109/ IAdCC.2013.6514270 .

Diederich, S., Brendel, A., \& M Kolbe, L. (2019). On conversational agents in information systems research: Analyzing the past to guide future work. Proceedings of the 14th International Conference on Wirtschaftsinformatik, December 2018, 1550-1564.

Dinev, T., \& Hart, P. (2006). An extended privacy Calculus model for Ecommerce transactions. Information Systems Research, 17(1), 6180. https://doi.org/10.1287/isre.1060.0080 .

Driscoll, M., Tobis, K., Gurka, D., Serafin, F., \& Carlson, E. (2015). Breaking down the silos to decrease internal diversions and patient flow delays. Nursing Administration Quarterly, 39(1), E1-E8. https://doi.org/10.1097/NAQ.0000000000000080 .

Dyke, G., Adamson, D., Howley, I., \& Rose, C. P. (2013). Enhancing scientific reasoning and discussion with conversational agents. IEEE Transactions on Learning Technologies, 6(3), 240-247. https://doi. org/10.1109/TLT.2013.25.

Eastlick, M. A., Lotz, S. L., \& Warrington, P. (2006). Understanding online B-to-C relationships: An integrated model of privacy concerns, trust, and commitment. Journal of Business Research, 59(8), 877-886. https://doi.org/10.1016/j.jbusres.2006.02.006 .

Eigner, I., Bodendorf, F., \& Wickramasinghe, N. (2019). Predicting highcost patients by machine learning: A case study in an Australian private hospital group. Proceedings of 11th International Conference on Bioinformatics and Computational Biology (BiCOB) (pp. 94-103). https://doi.org/10.29007/jw6h .

Elson, J. S., Derrick, D., \& Ligon, G. (2018). Examining trust and reliance in collaborations between humans and automated agents. Hawaii International Conference on System Sciences (HICSS). https://doi.org/10.24251/HICSS.2018.056 .

Ezziane, Z., Maruthappu, M., Gawn, L., Thompson, E. A., Athanasiou, T., \& Warren, O. J. (2012). Building effective clinical teams in healthcare. Journal of Health Organization and Management, 26(4), 428-436. https://doi.org/10.1108/14777261211251508

Feine, J., Gnewuch, U., Morana, S., \& Maedche, A. (2019). A taxonomy of social cues for conversational agents. International Journal of Human Computer Studies, 132, 138-161. https://doi.org/10.1016/j. ijhcs.2019.07.009 .

Ferlie, E., \& Shortell, S. (2001). Improving the quality of health Care in the United Kingdom and the United States: A framework for change. The Milbank Quarterly, 79(2), 281-315. https://doi.org/ 10.1111/1468-0009.00206

Finlayson, M. P., \& Raymont, A. (2012). Teamwork - general practitioners and practice nurses working together in New Zealand. Journal of Primary Health Care, 4(2), 150-155.

Fitrianie, S., Griffioen-Both, F., Spruit, S., Lancee, J., \& Beun, R. (2015). Automated dialogue generation for behavior intervention on mobile devices. Procedia Computer Science, 63, 236-243. https://doi.org/ 10.1016/j.procs.2015.08.339 .

Frick, N. R. J., Brünker, F., Ross, B. \& Stieglitz, S. (2019). Towards Successful Collaboration: Design Guidelines for AI-based Services enriching Information Systems in Organisations. Proceedings of the 30th Australasian Conference on Information Systems (ACIS), Fremantle, Australia

Frick, N.R.J., Brünker, F., Ross, B. \& Stieglitz, S. (2020). Design requirements for AI-based services enriching legacy information systems in enterprises: A managerial perspective. Proceedings of the 31st Australasian Conference on Information Systems (ACIS), Wellington, New Zealand.

Frick, N., Mirbabaie, M., Stieglitz, S. \& Salomon, J. (2021). Maneuvering through the stormy seas of digital transformation: the impact of empowering leadership on the AI readiness of enterprises. Journal of Decision Systems. https://doi.org/10.1080/ 12460125.2020.1870065

Følstad, A., Nordheim, C. B., \& Bjørkli, C. A. (2018). What makes users trust a Chatbot for customer service? An exploratory interview study. In: 5th International Conference on Internet Science (INSCI) (pp 194-208). https://doi.org/10.1007/978-3-030-01437716 .

Georgiadis, D. T. (2011). DY.M.A.CO.S. - dynamic Mobile agents for collaboration systems. Proceedings of the Mediterranean Conference on Information Systems (MCIS). https://aisel.aisnet. org/mcis2011/3

Gerhard, M., Moore, D. J., \& Hobbs, D. J. (2001). Continuous presence in collaborative virtual environments: Towards a hybrid avataragent model for user representation. In: de Antonio A., Aylett R., Ballin D. (Eds.) Intelligent Virtual Agents. IVA 2001. Lecture notes in computer science: Vol. 2190 (pp. 137-155). Springer, Berlin, Heidelberg. https://doi.org/10.1007/3-540-44812-8_12

Gilbert, J., Yan, J., \& Hoffman, S. (2010). A WHO report: Framework for action on interprofessional education and collaborative practice. Journal of Allied Health, 39(1), 196-197.

Girotto, J. A., Koltz, P. F., \& Drugas, G. (2010). Optimizing your operating room: Or, why large, traditional hospitals don't work. International Journal of Surgery, 8(5), 359-367. https://doi.org/ 10.1016/j.ijsu.2010.05.002 .

Gnewuch, U., Morana, S., \& Maedche, A. (2017). Towards designing cooperative and social conversational agents for customer service. Proceedings of the 38th International Conference on Information Systems (ICIS), Seoul.

Gnewuch, U., Meng, Y., \& Maedche, A. (2020). The effect of perceived similarity in dominance on customer self-disclosure to Chatbots in. 20th European Conference on Information Systems (ECIS).

Gopal, G., Suter-Crazzolara, C., Toldo, L., \& Eberhardt, W. (2018). Digital transformation in healthcare - architectures of present and future information technologies. Clinical Chemistry and Laboratory Medicine, 57(3), 328-335. https://doi.org/10.1515/cclm-2018-0658

Hagras, H. (2018). Toward human-understandable, explainable AI. Computer, 51(9), 28-36. https://doi.org/10.1109/MC.2018. 3620965 .

Han, S., \& Yang, H. (2018). Understanding adoption of intelligent personal assistants: A parasocial relationship perspective. Industrial Management \& Data Systems, 118(3), 618-636. https://doi.org/10. 1108/IMDS-05-2017-0214 
Handayani, P. W., Hidayanto, A. N., Sandhyaduhita, P. I., Kasiyah, \& Ayuningtyas, D. (2015). Strategic hospital services quality analysis in Indonesia. Expert Systems with Applications, 42(6), 3067-3078. https://doi.org/10.1016/j.eswa.2014.11.065 .

Hanna, N., \& Richards, D. (2014). The impact of communication on a human-agent shared mental model and team performance. In A. Lomuscio, P. Scerri, A. Bazzan, \& M. Huhns (Eds.), 13th International Conference on Autonomous Agents and Multiagent Systems, AAMAS 2014: Vol. 2 (pp. 1485-1486). Paris, France: International Foundation for Autonomous Agents and Multiagent Systems (IFAAMAS).

Hanseth, O., \& Bygstad, B. (2015). Flexible generification: ICT standardization strategies and service innovation in health care. European Journal of Information Systems, 24(6), 645-663. https://doi.org/10. 1057/ejis.2015.1 .

Hayashi, Y. (2018). Multiple pedagogical conversational agents to support learner-learner collaborative learning: Effects of splitting suggestion types. Cognitive Systems Research., 54, 246-257. https:// doi.org/10.1016/j.cogsys.2018.04.005.

Hayashi, Y., \& Ono, K. (2013). Embodied conversational agents as peer collaborators: Effects of multiplicity and modality. IEEE RO-MAN, 2013, 120-125. https://doi.org/10.1109/ROMAN.2013.6628465 .

Hussain, S., Ameri Sianaki, O., \& Ababneh, N. (2019). A survey on conversational agents/Chatbots classification and design techniques. In: L. Barolli, M. Takizawa, F. Xhafa, \& T. Enokido (Eds.), Primate life histories, sex roles, and adaptability, Vol. 927, (pp 946-956). Springer International Publishing. https://doi.org/10.1007/978-3030-15035-8 93 .

Iya, S., Chatterjee, J., \& G, J. S., \& Verma, R. (2017). Equipping healthcare professionals with facilitation skills for team building. Journal of Management and Commerce, 13(1), 33-38.

Jain, M. (2006). Decline in ICU adverse events, nosocomial infections and cost through a quality improvement initiative focusing on teamwork and culture change. Quality and Safety in Health Care, 15(4), 235-239. https://doi.org/10.1136/qshc.2005.016576.

Just, J. E., Cornwell, M. R., \& Huhns, M. N. (2005). Facilitating human collaboration with agents. Proceedings of the 38th annual Hawaii International Conference on System Sciences (HICSS). https://doi. org/10.1109/HICSS.2005.270 .

Kamar, E. (2016). Directions in hybrid intelligence: complementing AI systems with human intelligence. Proceedings of the 25th International Joint Conference on Artificial Intelligence (IJCAI\& 16). (pp. 4070-4073). AAAI Press.

Kanjanarat, P., Winterstein, A., Johns, T., Hatton, R., Gonzalez-Rothi, R., \& Segal, R. (2003). Nature of preventable adverse drug events in hospitals: A literature review. American Journal of Health-System Pharmacy, 60(17), 1750-1759. https://doi.org/10.1093/ajhp/60.17. 1750 .

Karau, S. J., \& Williams, K. D. (1993). Social loafing: A meta-analytic review and theoretical integration. Journal of Personality and Social Psychology, 65(4), 681-706. https://doi.org/10.1037/0022-3514.65. 4.681 .

Kassner, L., Hirmer, P., Wieland, M., Steimle, F., Königsberger, J., \& Mitschang, B. (2017). The social factory: Connecting people, machines and data in manufacturing for context-aware exception escalation. Hawaii International Conference on System Sciences (HICSS), (pp. 1673-1682). https://doi.org/10.24251/HICSS.2017. 202.

Kerly, A., Hall, P., \& Bull, S. (2007). Bringing chatbots into education: Towards natural language negotiation of open learner models. Knowledge-Based Systems, 20(2), 177-185. https://doi.org/10. 1016/j.knosys.2006.11.014 .

Kim, D. J. (2008). Self-perception-based versus transference-based trust determinants in computer-mediated transactions: A cross-cultural comparison study. Journal of Management Information Systems, 24, 13-45. https://doi.org/10.2753/MIS0742-1222240401 .
Kimani, E., Bickmore, T., Trinh, H., Ring, L., Paasche-Orlow, M., \& Magnani, J. (2016). A smartphone-based virtual agent for atrial fibrillation education and counseling. In: Traum D., Swartout W., Khooshabeh P., Kopp S., Scherer S., Leuski A. (Eds.) Intelligent Virtual Agents. IVA 2016. Lecture Notes in computer science: Vol. 10011. Springer, Cham. https://doi.org/10.1007/978-3-319-47665$0 \quad 11$

Klein, C., DiazGranados, D., Salas, E., Le, H., Burke, C., Lyons, R., \& Goodwin, G. (2009). Does team building work? Small Group Research, 40(2), 181-222. https://doi.org/10.1177/ 1046496408328821 .

Klinker, K., Wiesche, M., \& Krcmar, H. (2019). Digital Transformation in Health Care: Augmented Reality for Hands-Free Service Innovation. Information Systems Frontiers, 22, 1419-1431. https:// doi.org/10.1007/s10796-019-09937-7 .

Knijnenburg, B., \& Willemsen, M. (2016). Inferring capabilities of intelligent agents from their external traits. ACM Transactions on Interactive Intelligent Systems, 6(4), 1-25. https://doi.org/10.1145/ 2963106 .

Knote, R., Janson, A., Söllner, M., \& Leimeister, J. M. (2019). Classifying smart personal assistants: An empirical cluster analysis. Proceedings of the 52nd Hawaii International Conference on System Sciences (HICSS), 2024-2033. https://doi.org/10.24251/ hicss.2019.245

Kretzer, M., Gaß, O., \& Mädche, A. (2015). Design principles for diffusion of reports and innovative use of business intelligence platforms. Wirtschaftsinformatik Proceedings, 46 (pp. 675-690). https://aisel. aisnet.org/wi2015/46

Kripalani, S., LeFevre, F., Phillips, C. O., Williams, M. V., Basaviah, P., \& Baker, D. W. (2007). Deficits in communication and information transfer between hospital-based and primary care physicians: Implications for patient safety and continuity of care. Journal of the American Medical Association, 297(8), 831-841. https://doi. org/10.1001/jama.297.8.831 .

Kuckein, C., Schermann, M., Sunyaev, A., \& Krcmar, H. (2010). An exploratory study on physicians' diligence when dealing with patient data. Proceedings of the 18th European Conference on Information System (ECIS). https://aisel.aisnet.org/ecis2010/92

Kuziemsky, C., Weber-Jahnke, J., \& Williams, J. (2012). Engineering the healthcare collaboration space. Proceedings of the 4th International Workshop on Software Engineering in Health Care (SEHC) (pp. 51-57). https://doi.org/10.1109/SEHC.2012.6227009

Lankton, N., McKnight, D. H., \& Tripp, J. (2015). Technology, humanness, and trust: Rethinking Trust in Technology. Journal of the Association for Information Systems, 16(10), 880-918. https://doi. org/10.17705/1jais.00411 .

Laranjo, L., Dunn, A., Tong, H., Kocaballi, A., Chen, J., Bashir, R., Surian, D., Gallego, B., Magrabi, F., Lau, A., \& Coiera, E. (2018). Conversational agents in healthcare: A systematic review. Journal of the American Medical Informatics Association, 25(9), 12481258. https://doi.org/10.1093/jamia/ocy072 .

Laumer, S., Maier, C., \& Gubler, F. T. (2019). Chatbot acceptance in healthcare: Explaining user adoption of conversational agents for disease diagnosis. Proceedings of the 27th European Conference on Information Systems (ECIS), Stockholm \& Uppsala, Sweden. https://aisel.aisnet.org/ecis2019_rp/88

Laurenzi, E., Hinkelmann, K., Reimer, U., Van Der Merwe, A., Sibold, P., \& Endl, R. (2017). DSML4PTM: A domain-specific modelling language for patient transferal management. Proceedings of the 19th International Conference on Enterprise Information Systems (ICEIS) (pp. 520-531). https://doi.org/10.5220/ 0006388505200531 .

Lee, C., Jung, S., Kim, S., \& Lee, G. G. (2009). Example-based dialog modeling for practical multi-domain dialog system. Speech Communication, 51(5), 466-484. https://doi.org/10.1016/j.specom. 2009.01.008 . 
Leggat, S. (2007). Effective healthcare teams require effective team members: Defining teamwork competencies. BMC Health Services Research, 17(7). https://doi.org/10.1186/1472-6963-7-17 .

Lenz, R., \& Reichert, M. (2007). IT support for healthcare processes premises, challenges, perspectives. Data and Knowledge Engineering, 61(1), 39-58. https://doi.org/10.1016/j.datak.2006. 04.007 .

Leonard, M. (2004). The human factor: The critical importance of effective teamwork and communication in providing safe care. Quality and Safety in Health Care, 13(1), 85-90. https://doi.org/10.1136/ qshc. 2004.010033

Lim, M., Leichtenstern, K., Kriegel, M., Enz, S., Aylett, R., Vannini, N., Hall, L., \& Rizzo, P. (2011). Technology-enhanced role-play for social and emotional learning context - intercultural empathy. Entertainment Computing, 2, 223-231. https://doi.org/10.1016/j. entcom.2011.02.004 .

Luger, E., \& Sellen, A. (2016). "Like having a really bad PA": The Gulf between user expectation and experience of conversational agents. Proceedings of the 2016 CHI Conference on Human Factors in Computing Systems (pp. 5286-5297). https://doi.org/10.1145/ 2858036.2858288

Maedche, A., Legner, C., Benlian, A., Berger, B., Gimpel, H., Hess, T., Hinz, O., Morana, S., \& Söllner, M. (2019). AI-based digital assistants: Opportunities, threats, and research perspectives. Business and Information Systems Engineering, 61(4), 535-544. https://doi. org/10.1007/s12599-019-00600-8 .

Majeed Alhashem, A., Alquraini, H., \& Chowdhury, R. I. (2011). Factors influencing patient satisfaction in primary healthcare clinics in Kuwait. International Journal of Health Care Quality Assurance, 24(3), 249-262. https://doi.org/10.1108/09526861111116688

Marwan, M., Kartit, A., \& Ouahmane, H. (2016). Applying secure multiparty computation to improve collaboration in healthcare cloud. $3 \mathrm{rd}$ International Conference on Systems of Collaboration (SysCo) (pp. 1-6). https://doi.org/10.1109/SYSCO.2016.7831325 .

Mayring, P. (2014). Qualitative content analysis: Theoretical Foundation, Basic Procedures and Software Solution. Beltz Verlag.

Mayring, P. (2015). Qualitative content analysis: Theoretical background and procedures. In approaches to qualitative research in mathematics education. Advances in mathematics education. (pp. 365-380). Springer. https://doi.org/10.1007/978-94-017-9181-6_13 .

McCracken, S. S., \& Edwards, J. S. (2017). Implementing a knowledge management system within an NHS hospital: A case study exploring the roll-out of an electronic patient record (EPR). Knowledge Management Research \& Practice, 15(1), 1-11. https://doi.org/10. 1057/kmrp.2015.7

McDuff, D., \& Czerwinski, M. (2018). Designing emotionally sentient agents. Communications of the ACM, 61(12), 74-83. https://doi.org/ $10.1145 / 3186591$

McInnes, S., Peters, K., Bonney, A., \& Halcomb, E. (2015). An integrative review of facilitators and barriers influencing collaboration and teamwork between general practitioners and nurses working in general practice. Journal of Advanced Nursing, 71(9), 1973-1985. https://doi.org/10.1111/jan.12647.

McKnight, D. H., Choudhury, V., \& Kacmar, C. (2002). Developing and validating trust measures for e-commerce: An integrative typology. Information Systems Research, 13(3), 334-359. https://doi.org/10. 1287/isre.13.3.334.81

McTear, M., Callejas, Z., \& Griol, D. (2016). The conversational Interface. Talking to Smart Devices. Springer. https://doi.org/10. 1007/978-3-319-32967-3.

Meier, J., Boehm, A., Kielhorn, A., Dietz, A., Bohn, S., \& Neumuth, T. (2014). Design and evaluation of a multimedia electronic patient record "oncoflow" with clinical workflow assistance for head and neck tumor therapy. International Journal of Computer Assisted Radiology and Surgery, 9(6), 949-965. https://doi.org/10.1007/ s11548-014-0988-x .
Meuser, M., \& Nagel, U. (2009). The expert interview and changes in knowledge production. In: Bogner A., Littig B., Menz W. (Eds.) Interviewing Experts. Research Methods Series (pp. 17-42). Palgrave Macmillan, London, UK. https://doi.org/10.1057/ 97802302442762

Meyer von Wolff, R., Hobert, S., \& Schumann, M. (2019). How may i help you? - state of the art and open research questions for chatbots at the digital workplace. Proceedings of the 52nd Hawaii International Conference on System Sciences (HICSS), (pp. 95104). https://doi.org/10.24251/HICSS.2019.013

Miner, A., Chow, A., Adler, S., Zaitsev, I., Limited, E., Tero, P., Darcy, A., \& Paepcke, A. (2016). Conversational agents and mental health: Theory-informed assessment of language and affect. International conference on human agent interaction (pp. 123-130). https://doi. org/10.1145/2974804.2974820 .

Mirbabaie, M., Stieglitz, S., Brünker, F., Hofeditz, L., Ross, B., \& Frick, N. R. J. (2020). Understanding collaboration with virtual assistants The role of social identity and the extended self. Business \& Information Systems Engineering. https://doi.org/10.1007/s12599020-00672-x .

Mitchell, T., Cohen, W., Hruschka, E., Talukdar, P., Yang, B., Betteridge, J., Carlson, A., Dalvi, B., Gardner, M., Kisiel, B., Krishnamurthy, J., Lao, N., Mazaitis, K., Mohamed, T., Nakashole, N., Platanios, E., Ritter, A., Samadi, M., Settles, B., Wang, R., Wijaya, D., Gupta, A., Chen, X., Saparov, A., Greaves, M., \& Welling, J. (2018). Never-ending learning. Communications of the ACM, 61(5), 103-115. https://doi.org/10.1145/3191513 .

Mosadeghrad, A. M. (2013). Healthcare service quality: Towards a broad definition. International Journal of Health Care Quality Assurance, 26(3), 203-219. https://doi.org/10.1108/09526861311311409 .

Mosadeghrad, A. M. (2014). Factors influencing healthcare service quality. International journal of health policy and management, 3(2), 77-89. https://doi.org/10.15171/ijhpm.2014.65 .

Nabeth, T., Angehrn, A., \& Roda, C. (2003). Enhancing knowledge management systems with cognitive agents. Systèmes d'Information et Management, 8(2), 1-19.

Nakano, Y., \& Fukuhara, Y. (2012). Estimating conversational dominance in multiparty interaction. Proceedings of the 14th ACM International Conference on Multimodal Interaction (ICMI) (p. 77). https://doi.org/10.1145/2388676.2388699 .

Nasirian, F., Ahmadian, M., \& Lee, O.-K. (2017). AI-based voice assistant systems: Evaluating from the interaction and trust perspectives. 23rd Americas Conference on Information Systems.

Nezhad, H., Gunaratna, K., \& Cappi, J. (2017). eAssistant: Cognitive assistance for identification and auto-triage of actionable conversations. International Conference on World Wide Web Companion (pp. 89-98). https://doi.org/10.1145/3041021.3054147 .

Norman, D. (2013). The Design of Everyday Things: Revised and expanded edition. Basic Books.

Nunamaker, J. F., Derrick, D. C., Elkins, A. C., Burgoon, J. K., \& Patton, M. W. (2011). Embodied conversational agent-based kiosk for automated interviewing. Journal of Management Information Systems, 28(1), 17-48. https://doi.org/10.2753/MIS0742-1222280102 .

Orledge, J., Phillips, W. J., Murray, W. B., \& Lerant, A. (2012). The use of simulation in healthcare. Current Opinion in Critical Care, 18(4), 326-332. https://doi.org/10.1097/MCC.0b013e328353fb49 .

Ouldouali, L., Sabouret, N., \& Rich, C. (2017). A computational model of power in collaborative negotiation dialogues. In: Beskow J., Peters C., Castellano G., O\&;Sullivan C., Leite I., Kopp S. (Eds.) Intelligent Virtual Agents. IVA 2017. Lecture Notes in Computer Science: Vol. 10498. Springer, Cham. https://doi.org/10.1007/9783-319-67401-8 35

Paul, S., Ramaprasad, A., \& Wickramasinghe, N. (2016). Introduction to the technology mediated collaborations in healthcare Minitrack. 49th Hawaii International Conference on System Sciences (HICSS) (pp. 959-959). https://doi.org/10.1109/HICSS.2016.122 . 
Pavlou, P. (2001). Integrating trust in electronic commerce with the technology acceptance model: Model development and validation. Proceedings of the Americas Conference on Information Systems ( AMCIS). https://aisel.aisnet.org/amcis2001/159

Pereira, C., McNamara, A., Sorge, L., \& Arya, V. (2013). Personalizing public health: Your health avatar. Journal of the American Pharmacists Association, 53(2), 145-151. https://doi.org/10.1331/ JAPhA.2013.12207 .

Pfeuffer, N., Adam, M., Toutaoui, J., Hinz, O., Benlian, A., Pfeuffer, N., \& Toutaoui, J. (2019). Mr. and Mrs. conversational agent - gender stereotyping in judge-advisor systems and the role of egocentric Bias. 40th International Conference on Information Systems (ICIS). https://aisel.aisnet.org/icis2019/human_computer_interact/ human_computer_interact/2

Platt, N., Tarafdar, M., \& Williams, R. A. (2019). The complementary roles of health information systems and relational coordination in alcohol care pathways: The case of a U.K. hospital. Proceedings of the 27th European Conference on Information Systems (ECIS), Stockholm \& Uppsala, Sweden. https://aisel.aisnet.org/ecis2019_ rip/30

Prada, R., \& Paiva, A. (2009). Teaming up humans with autonomous synthetic characters. Artificial Intelligence, 173(1), 80-103. https:// doi.org/10.1016/j.artint.2008.08.006 .

Prados-Suárez, B., Molina, C., Peña Yañez, C., \& Prados De Reyes, M. (2012). Improving electronic health records retrieval using contexts. Expert Systems with Applications, 39(10), 8522-8536. https://doi. org/10.1016/j.eswa.2012.01.016 .

Preece, A., Webberley, W., Braines, D., Zaroukian, E., \& Bakdash, J. (2017). Sherlock: Experimental evaluation of a conversational agent for Mobile information tasks. IEEE Transactions on HumanMachine Systems, 47(6), 1017-1028. https://doi.org/10.1109/ THMS.2017.2700625.

Pynadath, D., \& Tambe, M. (2003). An automated teamwork infrastructure for heterogeneous software agents and humans. Autonomous Agents and Multi-Agent Systems, 7(2), 71-100. https://doi.org/10. 1023/A:1024176820874 .

Qu, S., \& Dumay, J. (2011). The qualitative research interview. Qualitative Research in Accounting \& Management, 8(3), 238264. https://doi.org/10.1108/11766091111162070 .

Robb, A., Cordar, A., Lampotang, S., White, C., Wendling, A., \& Lok, B. (2015). Teaming up with virtual humans: How other people change our perceptions of and behavior with virtual teammates. IEEE Transactions on Visualization and Computer Graphics, 21(4), 511-519. https://doi.org/10.1109/TVCG.2015.2391855 .

Romanow, C., \& Straub. (2012). Riding the wave: Past trends and future directions for health IT research. MIS Quarterly, 36(3), iii-x. https:// doi.org/10.2307/41703474 .

Rosen, M. A., DiazGranados, D., Dietz, A. S., Benishek, L. E., Thompson, D., Pronovost, P. J., \& Weaver, S. J. (2018). Teamwork in healthcare: Key discoveries enabling safer, high- quality care. American Psychologist, 73(4), 433-450. https://doi.org/10. 1037/amp0000298.

Rothenberger, L., Fabian, B., \& Arunov, E. (2019). Relevance of ethical guidelines for artificial intelligence - A survey and evaluation. Proceedings of the 27th European Conference on Information Systems (ECIS), Stockholm \& Uppsala, Sweden.https://aisel.aisnet. org/ecis2019_rip/26

Russel, S., \& Norvig, P. (2016). Artificial intelligence: A modern approach. Addison Wesley.

Saffarizadeh, K., Boodraj, M., \& Alashoor, T. M. (2017). Conversational assistants: Investigating privacy concerns, trust, and self-disclosure. 38 th International Conference on Information Systems (ICIS), Seoul, South Korea.

Salas, E., Rozell, D., Mullen, B., \& Driskell, J. (1999). The effect of team building on performance. Small Group Research, 30(3), 309-329. https://doi.org/10.1177/104649649903000303 .
Salas, E., Sims, D. E., \& Burke, C. S. (2005). Is there a "big five" in teamwork? Small Group Research, 36(5), 555-599. https://doi.org/ $10.1177 / 1046496405277134$.

Sargeant, J., Loney, E., \& Murphy, G. (2008). Effective interprofessional teams: "Contact is not enough" to build a team. Journal of Continuing Education in the Health Professions, 28(4), 228-234. https://doi.org/10.1002/chp.189 .

Schadewaldt, V., McInnes, E., Hiller, J., \& Gardner, A. (2013). Views and experiences of nurse practitioners and medical practitioners with collaborative practice in primary health care - an integrative review. BMC Family Practice, 14, 1-11. https://doi.org/10.1186/14712296-14-132 .

Schadewaldt, V., McInnes, E., Hiller, J., \& Gardner, A. (2014). Investigating characteristics of collaboration between nurse practitioners and medical practitioners in primary healthcare: A mixed methods multiple case study protocol. Journal of Advanced Nursing, 70(5), 1184-1193. https://doi.org/10.1111/jan.12269 .

Schmulian, A., \& Coetzee, S. A. (2019). The development of messenger bots for teaching and learning and accounting students' experience of the use thereof. British Journal of Educational Technology, 50(5), 2751-2777. https://doi.org/10.1111/bjet.12723 .

Seeber, I. (2019). How do facilitation interventions foster learning? The role of evaluation and coordination as causal mediators in idea convergence. Computers in Human Behavior, 94, 176-189. https://doi. org/10.1016/j.chb.2018.11.033 .

Seeber, I., Bittner, E., Briggs, R. O., de Vreede, G.-J., de Vreede, T., Druckenmiller, D., Maier, R., Merz, A. B., Oeste-Reiß, S., Randrup, N., Schwabe, G., \& Söllner, M. (2018). Machines as teammates: A collaboration research agenda. Hawaii International Conference on System Sciences (HICSS), (pp. 420-429). https:// doi.org/10.24251/HICSS.2018.055 .

Seeber, I., Waizenegger, L., Seidel, S., Morana, S., Benbasat, I., Benjamin, P., Benjamin Lowry, P., Seeber, P., \& Tech, V. (2019). Reinventing collaboration with autonomous technology-based agents. Proceedings of the 27th European Conference on Information Systems (ECIS), Stockholm \& Uppsala, Sweden. https://ssrn.com/abstract=3503833

Seeber, I., Bittner, E., Briggs, R. O., de Vreede, T., de Vreede, G.-J., Elkins, A., Maier, R., Merz, A. B., Oeste-Reiß, S., Randrup, N., Schwabe, G., \& Söllner, M. (2020a). Machines as teammates: A research agenda on $\mathrm{AI}$ in team collaboration. Information \& Management, 57(2), 103174. https://doi.org/10.1016/j.im.2019. 103174 .

Seeber, I., Waizenegger, L., Seidel, S., Morana, S., Benbasat, I., \& Lowry, P. B. (2020b). Collaborating with technology-based autonomous agents: Issues and research opportunities. Internet Research, 30(1), 1-18. https://doi.org/10.1108/INTR-12-2019-0503 .

Seeger, A., Pfeiffer, J., \& Heinzl, A. (2017). When do we need a human? Anthropomorphic design and trustworthiness of conversational agents. Proceedings of the AMCIS - Special Interest Group on Human-Computer Interaction. http://aisel.aisnet.org/sighci2017/15

Seymour, M., Riemer, K., \& Kay, J. (2018). Actors, avatars and agents: Potentials and implications of natural face Technology for the Creation of realistic visual presence. Journal of the association for Information Systems, 19, 953-981. https://doi.org/10.17705/1jais. 00515

Shaked, N. (2017). Avatars and virtual agents - Relationship interfaces for the elderly. Healthcare Technology Letters, 4(3), 83-87. https:// doi.org/10.1049/htl.2017.0009 .

Shamekhi, A., Liao, Q., Wang, D., Bellamy, R., \& Erickson, T. (2018). Face value? Exploring the effects of embodiment for a group facilitation agent. Proceedings of the 2018 CHI conference on human factors in computing systems (pp. 1-13). https://doi.org/10.1145/ 3173574.3173965 .

Sheridan, T., \& Hennessy, R. (1984). Research and modeling of supervisory control behavior. DTIC Document: Report of a workshop. 
Siau, K., \& Wang, W. (2018a). Building trust in artificial intelligence, machine learning, and robotics. Cutter Business Technology Journal, 31, 47-53.

Siau, Keng, \& Wang, W. (2018b). Ethical and moral issues with AI. Americas Conference on Information Systems (AMCIS).

Siddike, A. K., \& Kohda, Y. (2018). Towards a framework of trust determinants in people and cognitive assistants interactions. 51st Hawaii International Conference on System Sciences (HICSS). https://doi.org/10.24251/HICSS.2018.672

Siddike, A. K., Spohrer, J., Demirkan, H., \& Kohda, Y. (2018). People's interactions with cognitive assistants for enhanced performances. 51st Hawaii International Conference on System Sciences. https:// doi.org/10.24251/hicss.2018.205 .

Singh, A., Mehta, J. C., Anand, D., Nath, P., Pandey, B., \& Khamparia, A. (2020). An intelligent hybrid approach for hepatitis disease diagnosis: Combining enhanced $\mathrm{k}$-means clustering and improved ensemble learning. Expert Systems, 1-13. https://doi.org/10.1111/ exsy. 12526 .

Smith, H., Milberg, S., \& Burke, S. (1996). Information privacy: Measuring individuals' concerns about organizational practices. MIS Quarterly, 20(2), 167-196. https://doi.org/10.2307/249477 .

Smith-Jentsch, K., Baker, D., Salas, E., \& Cannon-Bowers, J. (2001). Uncovering differences in team competency requirements: The case of air traffic control teams. In: E. Salas, C. A. Bowers \& E. Edens (Eds.), Improving teamwork in organizations: Applications of resource management training (pp. 31-54). CRC Press.

Söllner, M., Hoffmann, A., \& Leimeister, J. M. (2016). Why different trust relationships matter for information systems users. European Journal of Information Systems, 25(3), 274-287. https://doi.org/10. 1057/ejis.2015.17 .

Spohrer, J., \& Banavar, G. (2015). Cognition as a service: An industry perspective. AI Magazine, 36(4), 71-86. https://doi.org/10.1609/ AIMAG.V36I4.2618

Stoeckli, E., Uebernickel, F., \& Brenner, W. (2018). Exploring affordances of slack integrations and their actualization within enterprises - towards an understanding of how Chatbots create value. Hawaii International Conference on System Sciences (HICSS) (pp. 2016-2025). https://doi.org/10.24251/hicss.2018.255

Strohmann, T., Fischer, S., Siemon, D., Brachten, F., Lattemann, C., Robra-Bissantz, S., \& Stieglitz, S. (2018). Virtual moderation assistance: Creating design guidelines for virtual assistants supporting creative workshops. Proceedings of the 22nd Pacific Asia conference on information systems (PACIS) (pp. 3580-3594). https://aisel. aisnet.org/pacis2018/80

Tannenbaum, S. I., Beard, R. L., \& Salas, E. (1992). Chapter 5 team building and its influence on team effectiveness: An examination of conceptual and empirical developments. Advances in Psychology, 82, 117-153. https://doi.org/10.1016/S0166-4115(08)62601-1 .

Tavanapour, N., \& Bittner, E. (2018). Automated facilitation for idea platforms: Design and evaluation of a Chatbot prototype. 39th International Conference on Information Systems (ICIS), San Francisco.

Tavanapour, N., Poser, M., \& Bittner, E. (2019). Supporting the idea generation process in citizen participation - toward an interactive system with a conversational agent as facilitator. 27th European Conference on Information Systems (ECIS2019), StockholmUppsala, Sweden.

Tegos, S., \& Demetriadis, S. (2017). Conversational agents improve peer learning through building on prior knowledge. Educational Technology and Society, 20(1), 99-111.

Tegos, S., Demetriadis, S., \& Karakostas, A. (2011). MentorChat: Introducing a configurable conversational agent as a tool for adaptive online collaboration support. 2011 15th Panhellenic Conference on Informatics, (pp. 13-17). https://doi.org/10.1109/ PCI.2011.24
Tegos, S., Demetriadis, S., \& Tsiatsos, T. (2012). Using a conversational agent for promoting collaborative language learning. International conference on intelligent networking and collaborative systems (pp. 162-165). https://doi.org/10.1109/iNCoS.2012.105.

Tegos, S., Demetriadis, S., \& Karakostas, A. (2015). Promoting academically productive talk with conversational agent interventions in collaborative learning settings. Computers and Education, 87, 309325. https://doi.org/10.1016/j.compedu.2015.07.014 .

Temple, J. (2006). Conducting research literature reviews: From the internet to paper. Journal of Advanced Nursing, 55(6), 792-792. https://doi.org/10.1111/j.1365-2648.2006.04033.x .

Traum, D., Rickel, J., Gratch, J., \& Marsella, S. (2003). Negotiation over tasks in hybrid human-agent teams for simulation-based training. Proceedings of the 2nd International Joint Conference on Autonomous Agents and Multiagent Systems (AAMAS). https://doi. org/10.1145/860575.860646

Tschan, F., Semmer, N., Gautschi, D., Hunziker, P., Spychiger, M., \& Marsch, S. (2006). Leading to recovery: Group performance and coordinative activities in medical emergency driven groups. Human Performance, 19(3), 277-304. https://doi.org/10.1207/ s15327043hup1903_5.

Tschan, F., Semmer, N., Gurtner, A., Bizzari, L., Spychiger, M., Breuer, M., \& Marsch, S. (2009). Explicit reasoning, confirmation Bias, and illusory Transactive memory. Small Group Research, 40(3), 271300. https://doi.org/10.1177/1046496409332928 .

vom Brocke, J, Simons, A., Niehaves, Riemer K., Plattfaut, R., Cleven, A., von Brocke, J., \& Reimer, K. (2009). Reconstructing the Giant: On the Importance of Rigour in Documenting the Literature Search Process. European Conference on Information Systems (ECIS). https://doi.org/10.1108/09600031211269721 .

vom Brocke, J., Simons, A., Riemer, K., Niehaves, B., Plattfaut, R., \& Cleven, A. (2015). Standing on the Shoulders of Giants: Challenges and Recommendations of Literature Search in Information Systems Research. Communications of the Association for Information Systems, 37(1). https://doi.org/10.17705/1CAIS.03709 .

von der Pütten, A. M., Krämer, N. C., Gratch, J., \& Kang, S.-H. (2010). "It doesn't matter what you are!" explaining social effects of agents and avatars. Computers in Human Behavior, 26(6), 1641-1650. https://doi.org/10.1016/j.chb.2010.06.012 .

Waizenegger, L., Seeber, I., Dawson, G., \& Desouza, K. (2020). Conversational agents - exploring generative mechanisms and second-hand effects of actualized technology affordances. Proceedings of the 53rd Hawaii International Conference on System Sciences (HICSS). https://doi.org/10.24251/HICSS.2020. 636 .

Wears, R. L., \& Berg, M. (2005). Computer technology and clinical work. Journal of the American Medical Association, 293(10), 1261-1263. https://doi.org/10.1001/jama.293.10.1261 .

Webster, J., \& Watson, R. (2002). Analyzing the past to prepare for the future: Writing a literature review. MIS Quarterly, 26(2), 13-23. https://doi.org/10.2307/4132319.

Winkler, R., Neuweiler, M. L., Leimeister, J. M., SÖllner, M., \& Rossini, F. C. (2019). Alexa, can you help us solve this problem? How conversations with smart personal assistant tutors increase task group outcomes. Conference on Human Factors in Computing Systems, (pp. 1-6). https://doi.org/10.1145/3290607.3313090 .

Wünderlich, N., \& Paluch, S. (2017). A Nice and friendly chat with a bot: User perceptions of AI-based service agents. 38th International Conference on Information Systems (ICIS) (pp. 1-11).

Xiao, Z., Zhou, M., \& Fu, W. (2019). Who should be my teammates: Using a conversational agent to understand individuals and help teaming. International conference on intelligent user interfaces (pp. 437-447). https://doi.org/10.1145/3301275.3302264 .

Xu, J., \& Topi, H. (2017). A conceptual model for user-system collaboration: Enhancing usability of complex information systems. 
Communications of the Association for Information Systems, 41(1), 775-800. https://doi.org/10.17705/1CAIS.04131 .

Yang, H., Yu, J., Zo, H., \& Choi, M. (2016). User acceptance of wearable devices: An extended perspective of perceived value. Telematics and Informatics, 33(2), 256-269. https://doi.org/10.1016/j.tele. 2015.08.007 .

Zumbach, J., Schönemann, J., \& Reimann, P. (2005). Analyzing and supporting collaboration in cooperative computer-mediated communication. Proceedings of the international conference on computer supported collaborative learning (pp. 758-767). https://doi.org/10. 3115/1149293.1149393 .

Zwaan, L., \& Singh, H. (2015). The challenges in defining and measuring diagnostic error. Diagnosis, 2(2), 97-103. https://doi.org/10.1515/ dx-2014-0069 .

Publisher's note Springer Nature remains neutral with regard to jurisdictional claims in published maps and institutional affiliations. 